\title{
A Compendium of Performance Metrics, Pricing Schemes, Optimization Objectives, and Solution Methodologies of Demand Side Management for the Smart Grid
}

\author{
Sadiq Ahmad ${ }^{1}\left(\mathbb{D}\right.$, Ayaz Ahmad $^{1}\left(\mathbb{D}\right.$, Muhammad Naeem ${ }^{1}$, Waleed Ejaz ${ }^{2, *} \mathbb{C}$ \\ and Hyung Seok Kim ${ }^{3, *}$ \\ 1 Department of Electrical \& Computer Engineering, COMSATS University Islamabad, Wah Campus, \\ Wah Cantonment 47040, Pakistan; engrsadiqahmad@gmail.com (S.A.); ayaz.ahmad@ciitwah.edu.pk (A.A.); \\ muhammadnaeem@gmail.com (M.N.) \\ 2 Department of Applied Science \& Engineering, Thompson Rivers University (TRU), Kamloops, \\ BC V2C 0C8, Canada \\ 3 Department of Information \& Communication Engineering, Sejong University, Seoul 143 747, Korea \\ * Correspondence: waleed.ejaz@ieee.org (W.E.); hyungkim@sejong.edu (H.S.K.); \\ Tel.: +1-250-828-5101 (W.E.); +82-02-3408-3696 (H.S.K.)
}

Received: 11 September 2018 ; Accepted: 13 October 2018 ; Published: 17 October 2018

\begin{abstract}
The curtailing of consumers' peak hours demands and filling the gap caused by the mismatch between generation and utilization in power systems is a challenging task and also a very hot topic in the current research era. Researchers of the conventional power grid in the traditional power setup are confronting difficulties to figure out the above problem. Smart grid technology can handle these issues efficiently. In the smart grid, consumer demand can be efficiently managed and handled by employing demand-side management (DSM) algorithms. In general, DSM is an important element of smart grid technology. It can shape the consumers' electricity demand curve according to the given load curve provided by the utilities/supplier. In this survey, we focused on DSM and potential applications of DSM in the smart grid. The review in this paper focuses on the research done over the last decade, to discuss the key concepts of DSM schemes employed for consumers' demand management. We review DSM schemes under various categories, i.e., direct load reduction, load scheduling, DSM based on various pricing schemes, DSM based on optimization types, DSM based on various solution approaches, and home energy management based DSM. A comprehensive review of DSM performance metrics, optimization objectives, and solution methodologies is' also provided in this survey. The role of distributed renewable energy resources (DERs) in achieving the optimization objectives and performance metrics is also revealed. The unpredictable nature of DERs and their impact on DSM are also exposed. The motivation of this paper is to contribute by providing a better understanding of DSM and the usage of DERs that can satisfy consumers' electricity demand with efficient scheduling to achieve the performance metrics and optimization objectives.
\end{abstract}

Keywords: demand side management; renewable energy resources; smart grid; demand response management; distributed energy generation; real time pricing; time of use tariff; load profile; peak to average power ratio

\section{Introduction}

Electricity consumption is rising day by day and the existing conventional setup is experiencing difficulties in generating enough power to meet the current energy demands. Almost all components/parts 
of industry and several aspects of our lives are dependent on electrical energy or electricity. In peak hours, the energy demand further increases and providing the consumers with their demanded loads becomes more challenging. With the traditional power grid, it is very difficult to meet the above challenges [1]. To solve the issue of high consumer demand and the mismatch between generation and utilization, smart grid technology along with energy efficient scheduling is one of the solutions. In this paper, we discuss smart grid technology along with efficient energy management procedures which can solve the above problem up to a certain level. The list of acronyms, notations, and symbols used throughout the paper are tabulated in Tables 1 and 2.

Table 1. List of acronyms and their descriptions.

\begin{tabular}{cc}
\hline Acronyms & Description \\
\hline CLU & Control logic unit \\
DERs & Distributed energy resources \\
DMPR & Disjoint multipath routing protocol \\
DSM & Demand side management \\
ECS & Energy consumption scheduling \\
EeA & Energy efficient appliances \\
EeB & Energy efficient building \\
GUI & Graphical user interface \\
HEMS & Home energy management system \\
HVAC & Heat ventilation and air conditioning \\
iHEM & In home energy management \\
LP & Linear programming \\
MILP & Mixed integer linear programming \\
OM & Optimization module \\
OREM & Optimization based residential energy management \\
PAPR & Peak to average power ratio \\
PDCA & Possible demand curve of the appliances \\
PSO & Particle swarm optimization \\
RTP & Real-time pricing \\
SHEM & Smart home energy management \\
VCG & Vickrey-Clark-Grove \\
VPP & Virtual power player \\
WSAN & Wireless sensor and actuator network \\
\hline
\end{tabular}

Table 2. Notations and symbols used in this paper.

\begin{tabular}{cc}
\hline Notation & Meaning \\
\hline$X_{n, a}^{t}$ & Total energy of consumers to be scheduled \\
$C()$. & Cost of consumers' energy to be scheduled \\
$t$ & Time of use of energy \\
$a$ & Consumers' appliances \\
$P_{\text {peak }}$ & Consumers' demand during peak hours \\
$E(t)$ & Essential load energy consumption of consumer $N$ \\
$\gamma_{N}^{m \text { max }}$ & Maximum power generated by consumer $N$ through DERs \\
$\tau$ & Delay time slots for flexible loads \\
$A_{i, n}$ & Scheduling time slots \\
$\alpha_{i, n}, \beta_{i, n}$ & Re-scheduling interval \\
$\hat{\alpha}_{i, n}, \hat{\beta}_{i, n}$ & Delay scheduling interval \\
$\omega_{i, n}$ & Preferred scheduling interval for the $i^{t h}$ flexible load of $n$ \\
$\chi_{i, n}^{o}(t)$ & consumers \\
$S()$. & Energy consumption of flexible load \\
$P e\left(b_{t}, Q_{t}\right)$ & Generated electricity \\
$L_{i}^{s t}(t)$ & Electricity price \\
$L_{i}^{b}(t)$ & Shiftable load \\
\hline
\end{tabular}


Table 2. Cont.

\begin{tabular}{cc}
\hline Notation & Meaning \\
\hline$N$ & Total number of consumers \\
$Z_{c}$ & Primary variable representing the energy cost \\
$S_{t}$ & Aggregated load of all consumers \\
$\triangle(t)$ & Time interval \\
$P^{t}$ & Power consumed by consumer \\
$U(t)$ & Function of energy consumed \\
$P(t), R(t)$ & Non renewable and renewable energy \\
\hline
\end{tabular}

\subsection{Overview of the Smart Grid}

The electric power supply system is becoming complex and intricate. For example, in 2004, there were thirty thousand generators to fulfill the requirements and demands of the consumer of three thousand utilities in the USA, while by 2014, that numbers of generators had increased to two hundred thousand [2]. In addition, millions of renewable generators are also utilized in the form of wind, solar, etc, which generate electric power and sell the surplus to the distribution grid. From the above reports, it is clear that the power system is becoming more complex with time and with the increase in the population. To deal with the complexity of the power system, an efficient and intelligent power grid is the eventual solution. In an electrical power system, the grid is referred to as the electricity system that consists of, or that supports, electricity generation, transmission, distribution, and control. The smart grid, also known as the smart power grid, is an intelligent grid composed of the above features of the traditional grid in an intelligent way. In addition, the smart grid employs the option of two-way communication along with electricity transformation [3]. The smart grid is also called the intergrid, futuregrid, or intragrid [4]. The smart grid represents a perception of the future power system, composed of advanced communication, sensing, and control technologies at the generation, transmission, and distribution levels in a consumer-friendly environment [5-7].

On the transmission and distribution levels in power systems, losses are a very crucial factor that reduces efficiency and also affects the reliability of the system [8]. Based on different survey reports, it is concluded that almost 210 billion $\mathrm{kWh}$ of energy loss occur throughout the world in one year in transportation from the generation station into the consumers' premises. In general, annual transmission and distribution losses are estimated to be 6\% [9]. The smart grid has the potential not only to reduce those losses from the power plant to end user devices but can also reduce the demand during peak hours $[4,10,11]$.

The smart grid also enables efficient electric transportation, utilization of renewable energy resources, and the reduction of carbon dioxide $\left(\mathrm{CO}_{2}\right)$ emissions, thereby providing a reliable and green power supply. The smart grid is composed of a bi-directional flow of electricity, smart and secure metering, along with energy consumption scheduling (ECS) devices and distributed energy resources (DERs). A general layout of the smart grid showing all these component is given in Figure 1. 


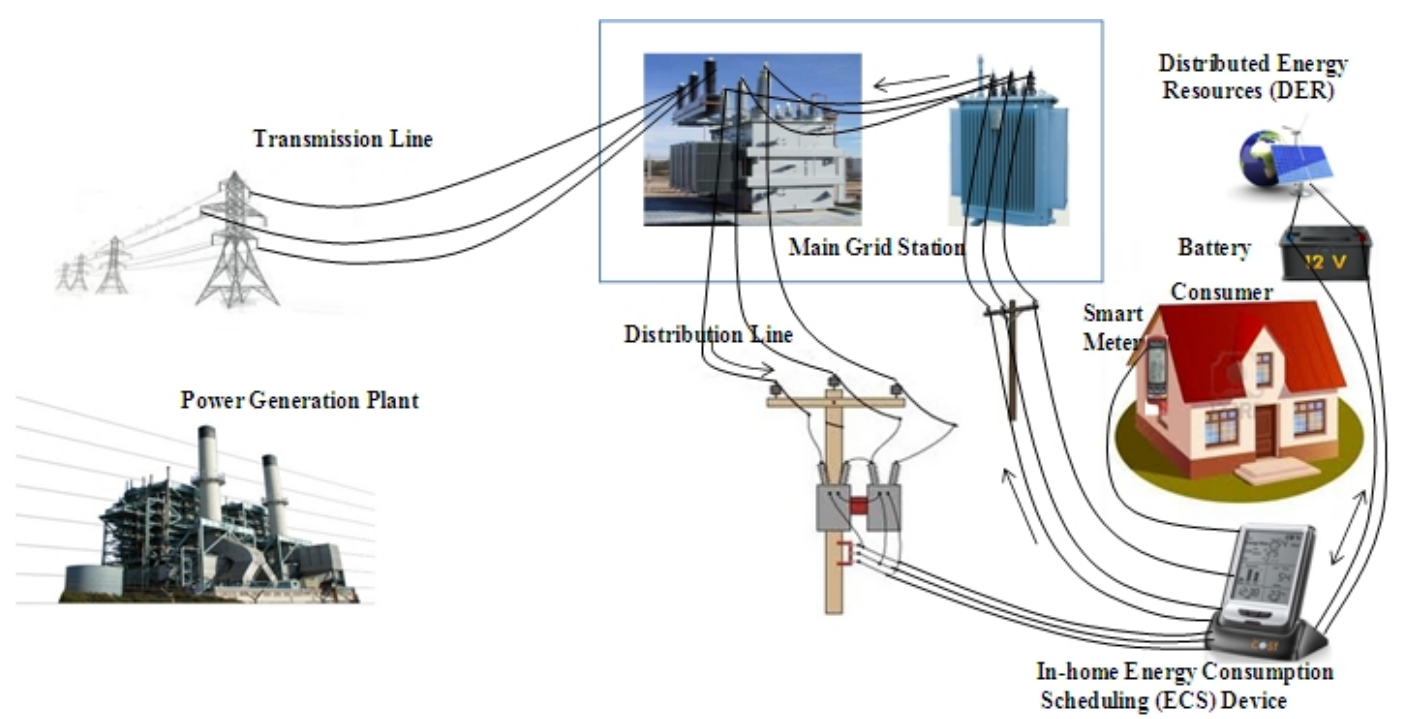

Figure 1. General layout of the smart grid's architecture.

\subsection{Comparison between the Smart and Conventional Grids}

In the traditional power grid, the grid carries power from the central generating station with a conventional distribution system, while in the smart grid, bi-directional flow of electricity between consumers and the grid is enabled by two-way communication and automated and smart distribution networks [12,13]. Through the use of modern and advanced information technologies, the smart grid can deliver power to the consumers' premises in an efficient way. Surveys on various basic concepts of the smart grid were conducted in [14-25]. Some of these surveys are summarized in Table 3.

Table 3. Comparison between the existing surveys and our proposed survey.

\begin{tabular}{cl}
$\begin{array}{c}\text { Existing Surveys } \\
\text { on the Smart } \\
\text { Grid }\end{array}$ & \multicolumn{1}{c}{ Objective } \\
\hline [26] & $\begin{array}{l}\text { In this paper, the authors review different demand response (DR) schemes for energy } \\
\text { management. The authors describe various incentive schemes in term of price } \\
\text { reduction to participate in the given DR. Moreover, the authors classify the DR } \\
\text { algorithms on the basis of system constraints and computational complexity. }\end{array}$ \\
\hline$[21]$ & $\begin{array}{l}\text { In this paper, the authors review all the communication media that is needed in smart } \\
\text { grid technology. }\end{array}$ \\
\hline$[27]$ & $\begin{array}{l}\text { In this paper, the authors highlight the potential applications of communication and } \\
\text { information technology in smart grid architecture that could be helped by an economic } \\
\text { and reliable power system. }\end{array}$ \\
\hline$[22]$ & $\begin{array}{l}\text { The authors review the communication networks that are needed for secure data } \\
\text { sharing and control among the various parts of the power system. }\end{array}$ \\
\hline$[28]$ & $\begin{array}{l}\text { This paper explains the challenges associated with the design of smart grid } \\
\text { communication networks. }\end{array}$ \\
\hline$[29]$ & $\begin{array}{l}\text { In this paper, the authors review various cyber security issues associated with } \\
\text { communication networks in the smart grid that can effect the reliability and system } \\
\text { operation of the power system. }\end{array}$ \\
\hline$[30]$ & $\begin{array}{l}\text { In this paper, the authors review the energy efficient communications networks among } \\
\text { the smart grid and the various data centers that manage the power system. }\end{array}$ \\
\hline $\begin{array}{l}\text { Numerous types of wireless communication and their feasibility of usage for different } \\
\text { areas of the power system are explored in this report. }\end{array}$ \\
\hline
\end{tabular}


Table 3. Cont.

\begin{tabular}{|c|c|}
\hline $\begin{array}{l}\text { Existing Survey } \\
\text { on the Smart } \\
\text { Grid }\end{array}$ & Objective \\
\hline$[24]$ & $\begin{array}{l}\text { The cyber security issues associated with the communication networks in the smart } \\
\text { grid are documented here. }\end{array}$ \\
\hline [25] & In this paper, the authors explore the advantages of the smart metering infrastructure. \\
\hline [31] & $\begin{array}{l}\text { The authors in this paper discuss the importance of prosumers and their relationship to } \\
\text { energy sharing for the sustainability of the power system. }\end{array}$ \\
\hline [32] & This paper discusses the application of the internet of thing (IoT) in the smart grid. \\
\hline [33] & $\begin{array}{l}\text { The worldwide implementation of the smart grid, related issues, and technological } \\
\text { advancements in the various components of the smart grid are discussed here. }\end{array}$ \\
\hline [34] & $\begin{array}{l}\text { The authors discuss the theoretical approaches used for the energy management in the } \\
\text { literature and also unify the terminologies, concepts, and existing models that use } \\
\text { energy management. }\end{array}$ \\
\hline [35] & $\begin{array}{l}\text { The authors in this paper highlight the challenges associated with the design of a } \\
\text { distribution network in the smart grid. }\end{array}$ \\
\hline [36] & $\begin{array}{l}\text { Energy conservation using prosumer excess energy, associated challenges, and } \\
\text { technological advancements in prosumers communication infrastructure are discussed } \\
\text { in this paper. }\end{array}$ \\
\hline [37] & $\begin{array}{l}\text { The authors discuss the significance of energy storage devices, advancements in these } \\
\text { devices, and their contributions to load management in the smart grid. }\end{array}$ \\
\hline [38] & Here, the authors summarize the technology associated with the smart grid. \\
\hline $\begin{array}{l}\text { Our proposed } \\
\text { survey }\end{array}$ & $\begin{array}{l}\text { In our survey, the objective is to classify and review all of the existing demand side } \\
\text { management (DSM) schemes that are used for consumer energy managemen, to figure } \\
\text { out the deficiencies and limitations of these schemes and to outline future } \\
\text { research directions. }\end{array}$ \\
\hline
\end{tabular}

A comparison of the traditional grid and the smart grid is given in Table $4[13,39,40]$. The smart grid can be explained through different technical perspectives, e.g., smart control and protection systems, the smart management system, and smart infrastructure. The tcommunication capability in the smart grid is the key feature which differentiates it from the conventional grid and which plays a vital role in the smart grid. Different researchers have focused on different perspectives to evaluate and explain the smart grid. The author in [41] demonstrated that instead of an expensive wired communication system, the wireless sensor and actuator network (WSAN) is more suitable for communication in the smart grid. Moreover, the use of wireless sensors and actuators can efficiently improve the performance of communication in smart grid [42]. With the help of these communication networks, the smart grid becomes able to efficiently manage energy consumption and solve the consumers' as well as the suppliers' issues.

Table 4. Highlights of traditional and smart grids [39].

\begin{tabular}{cc}
\hline Traditional Grid & Smart Grid \\
\hline Electromechanical & Digital \\
Minimal control & Pervasive control \\
One-way communication & Two-way communication \\
Few sensors & Sensors throughout \\
Manual monitoring & Self-monitoring \\
Manual restoration & Self-healing \\
Failures and blackouts & Adaptive and islanding \\
Few consumer choices & Many consumer choices \\
Centralized generation & Distributed generation \\
\hline
\end{tabular}


In smart grid technology, communication between utilities, consumers, and suppliers is of great importance. Consumer satisfaction and a reliable supply of electricity are possible when there is an efficient communication system. The survey conducted in [21-23,27-30] explored different communication media and all the related issues to these networks, which are tabulated in Table 3. The authors in [24] reviewed different security issues related to the communication network in smart grid technology.

On the distribution side, smart grid technology plays an important role in minimizing the energy cost by utilizing an energy management mechanism. From a consumer perspective, it is very important to reduce the energy cost in order to pay the minimal electricity bill. Moreover, the supplier wants to minimize the consumers' peak hours demands in order to not operate the peaker power plants which charge them highly. Energy cost minimization, electricity bill reduction, and the curtailment of demand during peak hours need an efficient energy management mechanism.

There are various surveys available in the literature that aim to disclose the various aspects of smart grid technology and its applications as energy management solutions for consumers as well as for suppliers. Some authors addressed energy management through using smart appliances at the consumers' premises and smart infrastructure, while some presented smart distributions for energy management. Some authors focused on smart generation and smart communication networks, while others surveyed efficient demand response algorithms provided by the supplier's end for energy management. A survey based on the smart infrastructure system and smart management system is presented by the authors in [38]. Smart infrastructure mainly depends upon smart metering and two-way communication between utilities and consumers. Smart metering is the key block in smart grid technology for efficient demand-side management (DSM). The importance of smart metering and its various applications is documented in [25]. Consumer demand management plays a vital role in power system stability. This can be done through planning, monitoring, and by implementing different techniques at the supplier as well as at the consumer end [43-51].

\subsection{Demand-Side Management and Demand Response Management}

The art that is used to manage consumers' energy consumption from suppliers end is named the demand response (DR) while managing the energy consumption at the consumers' premises according to the consumers' priorities and decision is known as DSM [52]. In the DR, the supplier imposes certain limitations on the consumers' energy consumption in order to stabilize the power system. Moreover, in the DR, the supplier does not care about the consumers' preferences and priorities. The DR is normally designed for the supplier's benefit. The DR and its application from the supplier's perspective are summarized by John in [26]. The survey in [26] is based on various optimization algorithms and pricing methods. The suppliers propose various DR schemes for consumer energy management. These DR schemes are based on multiple scheduling algorithms and different pricing schemes to manage consumers' electricity consumption. The proposed DR scheduling algorithm is based on a different optimization procedure through which the consumers are motivated to participate and adopt the given DR schemes. On the other side, DSM is an art that can be utilized at the consumers' premises by consumers to manage energy consumption. In DSM, the consumers' benefits are the primary objectives. The DSM scheme is valuable both for the consumers as well as for the supplier. The benefits of DSM are summarized in Table 5 .

Table 5. Benefits of DSM.

\begin{tabular}{cc}
\hline Consumer Benefits & Supplier Benefits \\
\hline Required demand will be fulfilled & Generation, transmission, and distribution costs will be reduced \\
Reliable service & Less capital will be required for generation, etc. \\
Reduction in electricity bills & System will be more efficient and flexible \\
Improved lifestyle & Better services for consumers \\
\hline
\end{tabular}




\subsection{Contributions of This Survey}

The contributions of this survey is to present the energy management solutions, performance metrics, and optimization objectives associated with energy management and also to enlist the role of the DERs in achieving these optimization objectives. We are motivated to enlighten the inner chemistry of energy management and to disclose the various classifications of energy management. Moreover, the motivation of the paper is to highlight the flaws, imperfections, and inadequacies happened in the existing DSM schemes in order to enhance the future research in the field of energy management. In this survey, we are inspired to accumulate all of the existing DSM approaches used to manage the consumers' demands and also, to focus on the minimization of generation cost, aggregated power consumption, the maximization of social welfare, and the reduction of consumers' electricity bills. A detailed summary and taxonomy of distributed management is presented in the paper. The role of DERs in attaining the aforementioned performance metrics is also elucidated in this paper.

Our contribution is different from the existing surveys as it presents: (a) an overall glimpse of DSM models and the current state-of-the-art; (b) a classification of DSM schemes based on optimization types, solution approaches, and energy pricing; (c) a classification of performance metrics related to DSM schemes; (d) game theoretic and real-time pricing approaches used for cost minimization and peak-to-average power ratio (PAPR) reduction; (e) an integration of DERs and their roles in DSM schemes; (f) theuncertainty and unpredictability of DERs and their impacts on DSM schemes. A comparison of our contribution to the existing surveys is given in Table 3.

\subsection{Paper Organization and Research Methodology}

To collect data for this paper we used major five search libraries including IEEE Xplore, ScienceDirect, Wiley Online Library, SpringerLink, and MDPI. The overall data collected from these libraries are summarized in Figure 2.

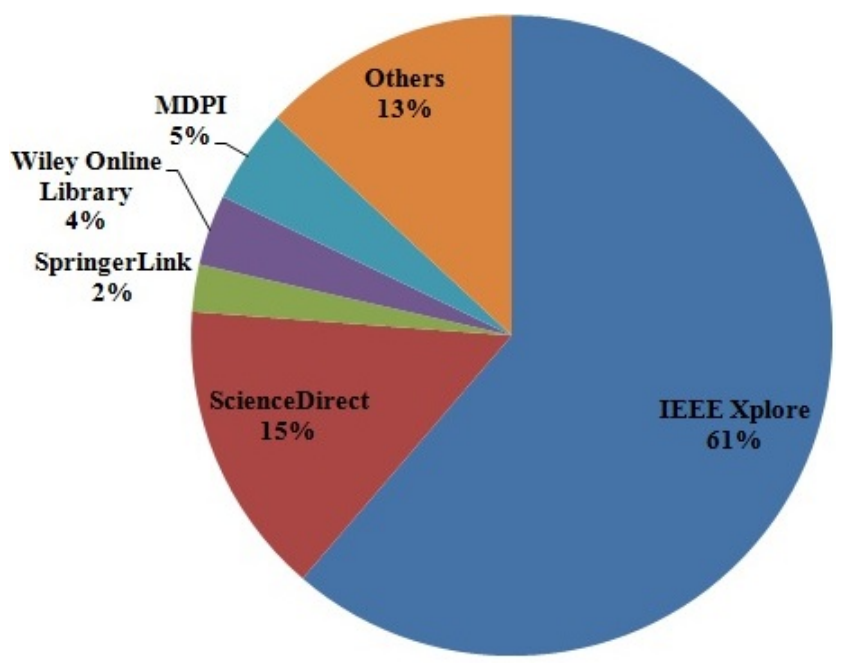

Figure 2. Database-wise review comparison.

We searched these databases by using the keywords 'smart grid', 'energy management', 'DSM', 'demand response management', 'optimization objectives of DSM', 'PAPR', 'DERs, and 'pricing tariff'. The systematic search work was done in three steps. In the first step, we searched IEEE Xplore for the mentioned keywords where we obtained 270 research papers including journals and conferences. As we mentioned earlier, our focus was on the last decade; therefore, in the second step, we filtered for the last decade and also excluded the low quality journals and conferences which resulted in 150 papers. In the third step, we filtered the download list by studying the titles and the abstracts which excluded another 43 articles. Similarly, we searched ScienceDirect, Wiley Online Library, SpringerLink, and MDPI simultaneously by using the mentioned keywords and obtained 75, 23, 18, 
and 15 research articles simultaneously. After step two, the given list reduced to 47, 13, 10 and 15 articles. Then, through studying the article titles and abstracts, the download lists reduced to 25, 6, 4, and 8. Besides the above libraries, we also searched the Scopus database, US Department of Energy and European Union electricity market to collect various energy consumption reports which yielded 22 papers. The year-wise published papers are summarized in Figure 3.

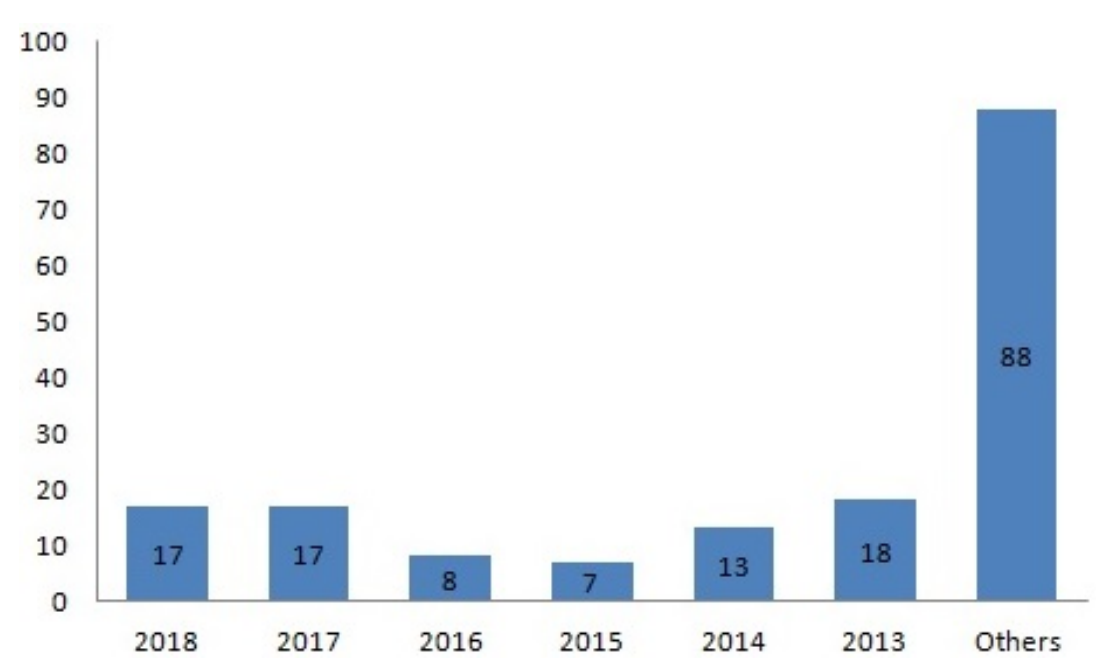

Figure 3. Annual publication year-wise comparison.

The rest of the paper is structured as follows. The general layout of DSM, the classifications of DSM and their roles in cost minimization are discussed in Section 2. Section 3 elucidates the use of DERs and their integration into the main grid. Moreover, this section also explains how DERs can help a given DSM scheme to achieve various performance metrics. The future research directions are outlined in Section 4. The paper is concluded in Section 5.

The words consumer and end-user are used interchangeably throughout this survey.

\section{Demand-Side Management Classifications and Their Roles in Cost Minimization}

Managing the consumer load in order to shape the supplier load curve in an efficient way is a hot topic in the current research community. DSM is an important component of smart grid technology. DSM refers to programmes, algorithms, and management activities adopted by consumers to optimally utilize the available electricity [12,53]. By implementing an efficient DSM algorithm, the consumers can modify their energy consumption patterns and minimize their electricity bills which can in turn, reduce the production costs of energy. DSM enables the consumers and gives them a choice to reduce their electricity costs by employing energy conservation techniques and shifting the peak hours' load to off-peak hours. The benefits assessment of DSM for USA and UK are documented in [54-56], where the authors report that DSM improves the distribution network's efficiency, resulting in reduced $\mathrm{CO}_{2}$ emissions by maximizing the use of renewable energy resources.

In this section, we discuss various subtopics including the classification of DSM and cost minimization by utilizing efficient DSM schemes. The subsection classification of DSM consists of direct load reduction, load scheduling, DSM based on energy pricing, DSM based on energy consumption scheduling, and DSM based on home energy management. Similarly, the minimization of subsection costs by utilizing efficient DSM schemes is classified on the basis of various approaches and methodologies used for the formulation of cost minimization problems and their solutions which includes cost minimization using the game theory approach and cost minimization using a DSM scheme based on real-time pricing RTP. 


\subsection{Classification of DSM}

DSM plays a vital role in minimizing the consumer load and shaping consumer demand according to the load curve provided by the generation or distribution of companies. An adequate DSM scheme can minimize the consumers' electricity bills, generation costs, peak hours' demands, etc. [57]. Moreover, the load curve of the consumers demands can also be flattened through efficient DSM. An efficient DSM scheme can achieve various performance metrics. These performance metrics include the reduction of consumers' electricity bills, the reduction of electricity demand during peak hours, generation cost minimization, demand curve flattening, consumer privacy, priority of consumer preferences and satisfaction, $\mathrm{CO}_{2}$ emission reduction, and social welfare maximization. In the literature, various research articles are available on DSM. In all of these research papers, the authors tried to achieve one or a combination of the above-described objectives of DSM. We summarize these papers and classify them according to the performance metrics achieved by each author, as shown in Table 6 .

Table 6. Classification of performance metrics related to energy management in the smart grid.

\begin{tabular}{|c|c|c|c|c|c|c|c|}
\hline Ref. No. & Centralized & Decentralized & $\begin{array}{l}\text { Consumer } \\
\text { Privacy }\end{array}$ & $\begin{array}{c}\text { Consumer } \\
\text { Preference, Priority, } \\
\text { \& Satisfaction }\end{array}$ & $\begin{array}{c}\text { PAPR } \\
\text { Reduction }\end{array}$ & $\underset{\text { Minimization }}{\text { Cost }}$ & $\begin{array}{c}\text { Use of DERs \& } \\
\text { Their } \\
\text { Integration }\end{array}$ \\
\hline [58] & $\checkmark$ & & & & & $\checkmark$ & $\checkmark$ \\
\hline [2] & $\checkmark$ & & $\checkmark$ & & $\checkmark$ & $\checkmark$ & $\checkmark$ \\
\hline [59] & $\checkmark$ & & $\checkmark$ & & & $\checkmark$ & \\
\hline [60] & $\checkmark$ & & $\checkmark$ & $\checkmark$ & $\checkmark$ & $\checkmark$ & \\
\hline [6] & $\checkmark$ & & $\checkmark$ & & & & \\
\hline [61] & & $\checkmark$ & & & $\checkmark$ & & \\
\hline [62] & $\checkmark$ & & & $\checkmark$ & & & \\
\hline$[4]$ & & $\checkmark$ & $\checkmark$ & & $\checkmark$ & $\checkmark$ & \\
\hline [63] & & $\checkmark$ & & & $\checkmark$ & & \\
\hline$[11,43,64]$ & $\checkmark$ & & & & & & \\
\hline$[65]$ & & $\begin{array}{l}\checkmark \\
\checkmark\end{array}$ & & $\checkmark$ & $\checkmark$ & $\checkmark$ & $\checkmark$ \\
\hline$[67-75]$ & $\checkmark$ & & & & & & $\checkmark$ \\
\hline [76] & $\checkmark$ & & & & & $\checkmark$ & \\
\hline$[77,78]$ & & $\checkmark$ & & & & $\checkmark$ & $\checkmark$ \\
\hline [79] & $\checkmark$ & & & & $\checkmark$ & & \\
\hline [80] & & $\checkmark$ & & & $\checkmark$ & & \\
\hline [81] & & $\checkmark$ & & $\checkmark$ & $\checkmark$ & & \\
\hline [82] & & $\checkmark$ & & & $\checkmark$ & $\checkmark$ & \\
\hline$[46,50,83]$ & $\checkmark$ & & & & $\checkmark$ & $\checkmark$ & \\
\hline$[47,84]$ & $\checkmark$ & & & $\checkmark$ & & & \\
\hline [85] & & $\checkmark$ & & & $\checkmark$ & & \\
\hline [86] & $\checkmark$ & & & $\checkmark$ & & & $\checkmark$ \\
\hline [87-89] & & $\checkmark$ & & & $\checkmark$ & $\checkmark$ & \\
\hline$[90,91]$ & $\checkmark$ & & $\checkmark$ & $\checkmark$ & $\checkmark$ & $\checkmark$ & \\
\hline [92] & & $\checkmark$ & $\checkmark$ & $\checkmark$ & $\checkmark$ & $\checkmark$ & $\checkmark$ \\
\hline [93] & $\checkmark$ & & $\checkmark$ & $\checkmark$ & & & \\
\hline [94] & & $\checkmark$ & $\checkmark$ & $\checkmark$ & & $\checkmark$ & \\
\hline$[95,96]$ & & $\checkmark$ & & & & & $\checkmark$ \\
\hline [97] & & $\checkmark$ & $\checkmark$ & & & & $\checkmark$ \\
\hline$[98]$ & & $\checkmark$ & & $\checkmark$ & $\checkmark$ & $\checkmark$ & \\
\hline [99] & $\checkmark$ & & & $\checkmark$ & $\checkmark$ & & \\
\hline [52] & & & & $\checkmark$ & & & \\
\hline [100] & & & $\checkmark$ & & $\checkmark$ & & \\
\hline [101] & & & & $\checkmark$ & & & \\
\hline [102] & & & $\checkmark$ & $\checkmark$ & & & $\checkmark$ \\
\hline
\end{tabular}

Consumer demand can be managed either directly by installing sensors inside or near to the home appliances or by shifting the high power rating devices into off-peak hours. For this purpose, DSM has been classified into two main types: direct load reduction and load scheduling.

Direct load reduction can be further classified into two types: by the use of energy efficient appliances and by the use of energy efficient buildings [103]. In the same way, load scheduling is also divided into two types: centralized and distributed scheduling identifies, as shown in Table 6. A flow diagram of DSM classification along with relevant references is given in Figure 4. 


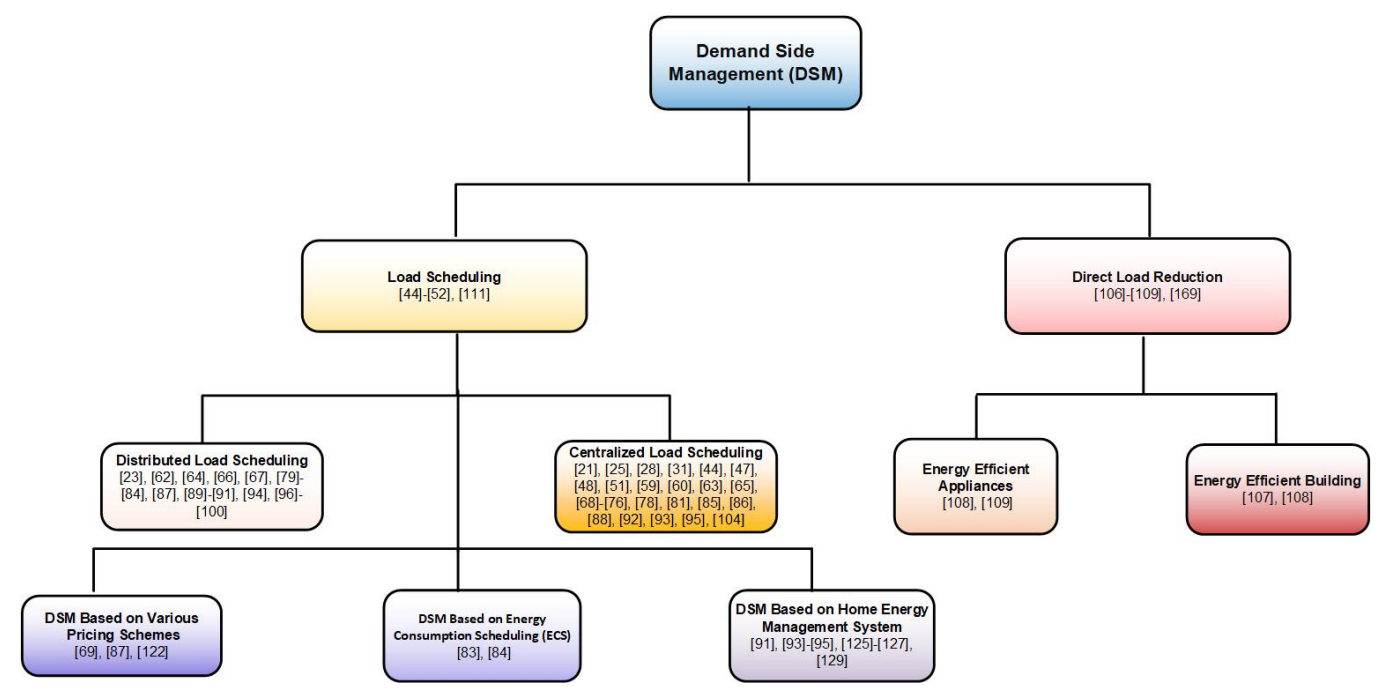

Figure 4. Classification of DSM.

\subsubsection{Direct Load Reduction}

In this type of DSM, consumer demand can be managed efficiently by constructing energy efficient building $(\mathrm{EeB})$ and by utilizing energy efficient appliances (EeA). In EeB, there is a balance between energy consumption and energy supplied by the supplier through environmental changes. The EeBs are designed based on the energy solution, i.e., in summer, these buildings are self-cooled, while in winter it does not require much energy for heating. Similarly, in EeA, the appliances are made intelligent by installing sensors inside them or in their vicinity to minimize energy consumption [104-107].

\subsubsection{Load Scheduling}

In this type of DSM, consumer demand is regulated by employing energy efficient algorithms and optimal demand side management schemes. The optimality of these schemes and algorithms is generally measured in terms of minimization of the peak-to-average power ratio (PAPR), generation cost, and consumers' electricity bills. PAPR is reduced by shifting the high power rating appliances to off-peak hours [108]. Load scheduling is further classified into subclasses which include DSM based on energy pricing, DSM based on energy consumption scheduling, and DSM based on home energy management. These are discussed in detail in the upcoming subsection, as shown in Figure 4.

Consumer demand plays an important role in energy management systems. Various DSM schemes have been utilized to manage consumer load. A dynamic programming based DSM scheme was suggested by the authors of $[89,109]$. In this algorithm, the consumer's profit is maximized and the overall cost of production by using the smart distributed network is minimized. The demand during peak hours is one of the critical and most important factors in DSM. The authors of [110] used a fuzzy system approach to reduce the consumers' peak hours demands. In this fuzzy system based DSM, the authors gave input in the form of demand during peak hours at one end of the system and get the the corresponding DSM as the output of the system. Similarly, the authors of [111] proposed a DSM scheme considering multiple utilities based on game theory. The game consists of two levels; at the lower level, i.e., an evolutionary game, the consumers manage their demands and power prices correspondingly and at the upper level, the problem of multiple suppliers is modeled as a non-cooperative game.

There are plenty of research articles available in the literature with the aim of minimizing costs, consumers' electricity bills, and the peak to average power ratio, etc, by employing efficient DSM schemes. These research articles along with the objectives achieved and advantages associated with each article are summarized in Table 7 . To achieve these objectives, authors have utilized different 
optimization approaches. The various optimization approaches employed in DSM schemes along with the relevant references are shown in Figure 5.

Table 7. Optimization objectives and outcomes.

\begin{tabular}{|c|c|c|}
\hline Ref. & Objective & Advantage/ Outcomes \\
\hline [58] & \multirow{6}{*}{ Cost minimization } & $\begin{array}{l}\text { Maximizes the consumers' payoff by improving the economic efficiency } \\
\text { of the residential consumption }\end{array}$ \\
\hline [77] & & Maximizes the welfare of consumers \\
\hline [89] & & Maximizes consumers profit \\
\hline [93] & & PAPR reduces \\
\hline [95] & & Minimizes the operation cost \\
\hline [98] & & Reduces the consumers' electricity expenses \\
\hline [112] & Cost and PAPR reduction & Minimizes consumers' bills by up to $25 \%$ \\
\hline [76] & \multirow{5}{*}{ Electricity bill reduction } & Minimizes the waiting time of the appliances \\
\hline [113] & & Minimizes consumers' electricity consumption \\
\hline [81] & & The total generation cost is minimized at the Nash equilibrium point \\
\hline [86] & & Reduces the bills by up to $22 \%$ \\
\hline [91] & & Minimizes the cost of energy \\
\hline [87] & Electricity cost reduction & Minimizes the total average cost of electricity of all consumers \\
\hline [114] & $\begin{array}{l}\text { Electricity cost reduction and stabilization } \\
\text { of the load profile }\end{array}$ & Minimizes electricity consumption of all consumers \\
\hline [115] & Generation cost and PAPR minimization & Minimizes the consumers' energy costs \\
\hline [62] & Maximization of the overall utility & Satisfies the budget limits \\
\hline [80] & Maximization of the welfare of consumers & Minimizes transmission losses \\
\hline [96] & Maximization of the generation & Maximizes the generation capacity \\
\hline [116] & Maximization of the social welfare & Minimizes the electricity costs which, in turn, maximizes the welfare \\
\hline [117] & Maximization of the consumer profit & Minimizes the consumers' electricity bills \\
\hline [118] & Minimization of the generation cost & $\begin{array}{l}\text { Reduces the generation cost and demand during peak hours which } \\
\text { flattens the demanded load profile }\end{array}$ \\
\hline [92] & $\begin{array}{l}\text { Minimization of the generation cost and } \\
\text { demand during peak hours }\end{array}$ & $\begin{array}{l}\text { Reduces the generation cost and demand during peak hours which } \\
\text { flattens the demanded load profile }\end{array}$ \\
\hline [119] & $\begin{array}{l}\text { Minimization of the discomfort level of } \\
\text { consumers }\end{array}$ & Improves the satisfaction of consumers \\
\hline [85] & Minimization of the peak demand & Reduces the capital expenditure \\
\hline$[82,83]$ & \multirow{2}{*}{ PAPR reduction } & Minimizes the electricity bills \\
\hline [61] & & Reduces the PAPR and maximizes the consumers' social welfare \\
\hline [120] & Maximization of consumers' welfare & \\
\hline [111] & $\begin{array}{l}\text { Demand during peak hours and consumers' } \\
\text { bills }\end{array}$ & Considers multiple utilities \\
\hline [110] & Reduction of peak hours demand & $\begin{array}{l}\text { The proposed system can be applied for multiple inputs, like temperature } \\
\text { changes, etc. }\end{array}$ \\
\hline [68] & Price reduction and reliability & Minimizes energy cost \\
\hline [97] & Reduction of energy consumption & Minimizes the imbalance caused by DERs on the main grid \\
\hline
\end{tabular}

Load scheduling is further classified into subclasses. The details for these subclasses are provided as follows. 


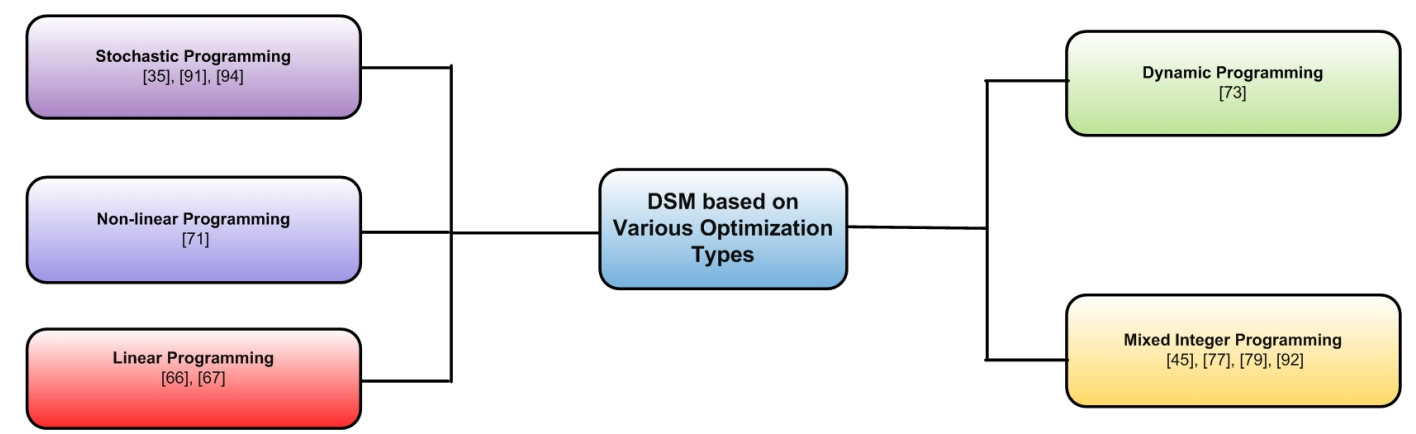

(a) Various optimization types.

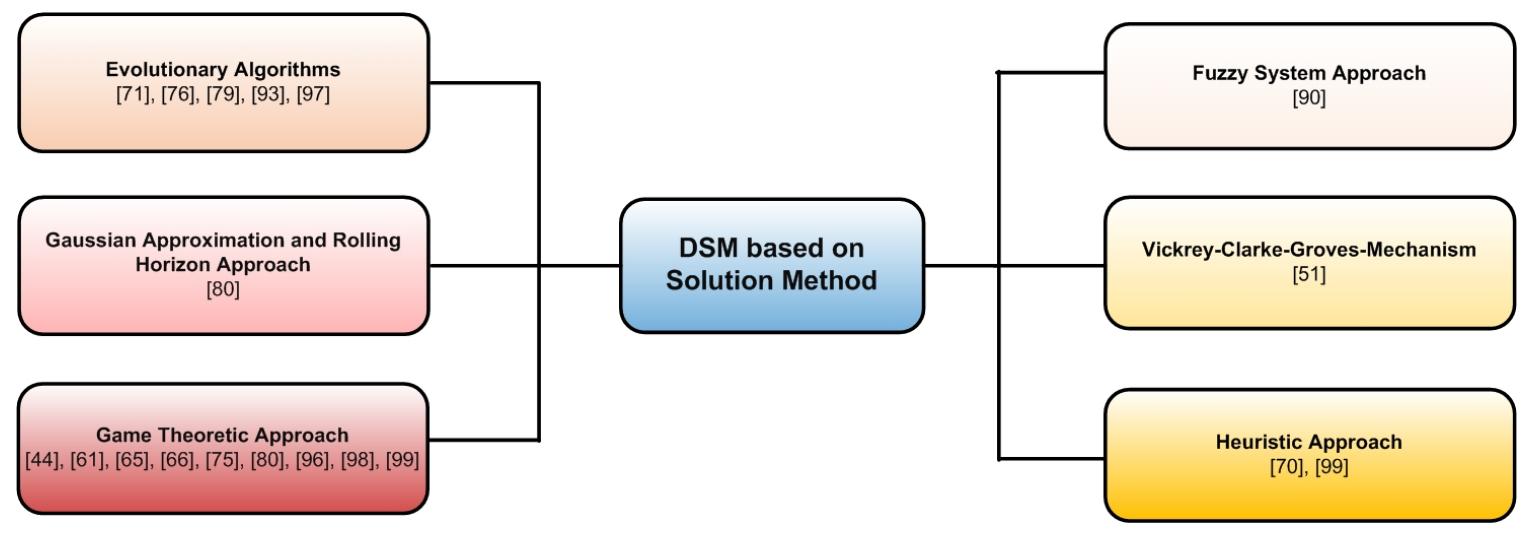

(b) Solution methods

Figure 5. Optimization types and various methods for their solution.

\section{DSM Based on Energy Pricing}

There are increases/decreases in the electricity price with increases or decreases in the electricity demand. During peak hours, the suppliers increase their electricity prices as they operate the peaker power plants, while in off-peak hours, the nominal price is used. By managing the consumers' demands during peak hours, the electricity bills that were at the peak can be reduced. There are many pricing schemes available in the literature, i.e., real-time pricing (RTP), fixed pricing, inclining block rate (IBR), customer reward (CR), net sale/purchase and time of use (TOU), etc. All these various pricing schemes and the relevant articles are summarized in Table 8. RTP pricing can be managed by the consumers themselves; , therefore, if the consumers curtail their demands, they will be awarded some incentives like a reduction in price and continuous and reliable supply.

We categorized all of the existing DSM frameworks on the basis of pricing schemes. For example, the authors in [68] proposed a DSM technique based on game theory to schedule energy consumption by using a smart pricing scheme. This technique benefits the consumer in terms of providing a price reduction and a reliable energy supply. Moreover, the authors also maximized the social welfare. One of the DSM schemes used by the authors in [86] is the RTP management scheme which has the objective of reduing the consumers' bills and managing the demanded loads of the consumers. The authors presented a possible demand curve of the appliances (PDCA) of different consumers by using the proposed algorithms. Furthermore, the authors implemented the scheme for two different case studies and concluded that the proposed scheme reduces the consumers electricity bills by $8 \%$ to $22 \%$ in summer. 
Table 8. Categorizes of the existing DSM schemes on the basis of pricing schemes and DERs.

\begin{tabular}{|c|c|c|c|c|}
\hline Ref. & Objective & Pricing Scheme & Optimization Technique & $\begin{array}{l}\text { Renewable } \\
\text { or DERs }\end{array}$ \\
\hline$[95,112]$ & \multirow{2}{*}{ Cost minimization } & Fixed price & Particle swarm optimization approach & $\checkmark$ \\
\hline [115] & & Net sale/purchase & Game theoretic approach & $\checkmark$ \\
\hline [114] & $\begin{array}{l}\text { Cost reduction and flattening of the } \\
\text { demand curve }\end{array}$ & RTP & Multi objective optimization approach & $\checkmark$ \\
\hline [121] & Curtailing peak hours demand & RTP & Particle swarm optimization approach & $\checkmark$ \\
\hline [84] & $\begin{array}{l}\text { Flattening of the demand profile and } \\
\text { consumer discomfort minimization }\end{array}$ & RTP & Greedy scheduling algorithms & $\checkmark$ \\
\hline [117] & Maximization of consumers' welfare & RTP & Stochastic optimization approach & $\checkmark$ \\
\hline [62] & Maximization of the overall utility & TOU & Mixed integer non-linear programming & \\
\hline [86] & Minimization of electricity bills & RTP & Heuristic optimization & \\
\hline$[82,83]$ & $\begin{array}{l}\text { Minimization of consumers' } \\
\text { electricity bills and PAPR }\end{array}$ & $\mathrm{RPT}$ & Linear programming & \\
\hline [88] & $\begin{array}{l}\text { Minimization of demand during } \\
\text { peak hours }\end{array}$ & RTP & Enumeration approach (set theory) & $\checkmark$ \\
\hline [99] & $\begin{array}{l}\text { Minimization of PAPR and } \\
\text { consumers' discomfort level }\end{array}$ & $\begin{array}{l}\text { Customer reward (CR) } \\
\text { and time of use (TOU) }\end{array}$ & & $\checkmark$ \\
\hline [122] & Minimization of peak hour demand & Net sale/purchase & Linear programming & $\checkmark$ \\
\hline [123] & $\begin{array}{l}\text { Minimization of peak hour demand } \\
\text { and consumers' bills }\end{array}$ & Net sale/purchase & $\begin{array}{c}\text { Enhanced differential evolution (EDE) } \\
\text { algorithm }\end{array}$ & \\
\hline [78] & $\begin{array}{l}\text { Minimization of the losses in the } \\
\text { distribution network }\end{array}$ & RTP & Linear programming & $\checkmark$ \\
\hline [98] & Price reduction and reliability & $\begin{array}{l}\text { RTP and inclining } \\
\text { block rate (IBR) }\end{array}$ & Multi-objective optimization approach & \\
\hline$[58]$ & \multirow{2}{*}{ Reduction of energy cost } & RTP & Fractional programming approach & $\checkmark$ \\
\hline [87] & & RTP & Lyapunov optimization theory & $\checkmark$ \\
\hline [74] & Reliable power supply & RTP & Convex optimization & $\checkmark$ \\
\hline
\end{tabular}

In [121], the authors investigated a dynamic energy management scheme based on the use of dynamic prices to reduce the consumers' demands during peak hours and improve the system's efficiency. The authors considered the use of a flexible load, e.g., the heat ventilation and air conditioning (HVAC) and heating systems of consumers, controlled through a proposed control strategy. The control strategy shifts this equipment into off-peak hours based on a dynamic pricing method. The retail price is updated every $15 \mathrm{~min}$ from the supplier end. The control strategy compares the retail price with the threshold set by the consumers, and this control strategy is operated through a dynamic demand response controller. The proposed scheme reduces the annual energy costs by up to $9 \%$.

\section{DSM Based on Energy Consumption Scheduling (ECS)}

DSM can be carried out through energy consumption scheduling (ECS). Various home energy management technique based on ECS are available in the literature. An optimization based residential load control scheme based on simple linear programming (LP) using the concepts of ECS was proposed in $[82,83]$. The authors proposed a mathematical model to represent the residential load control. The proposed scheme works on RTP which requires a price predictor. The price predictor collects information about the prices from yesterday, the day before yesterday, and for the same day in the previous week, and on the basis of this information, it predicts the price per $\mathrm{kWh}$ in real-time. The price predictor and ECS device of [82] are shown in Figure 6. The scheme in [82,83] significantly reduces the peak load which results in the reduction of the PAPR and the demanded load for different scenarios. 


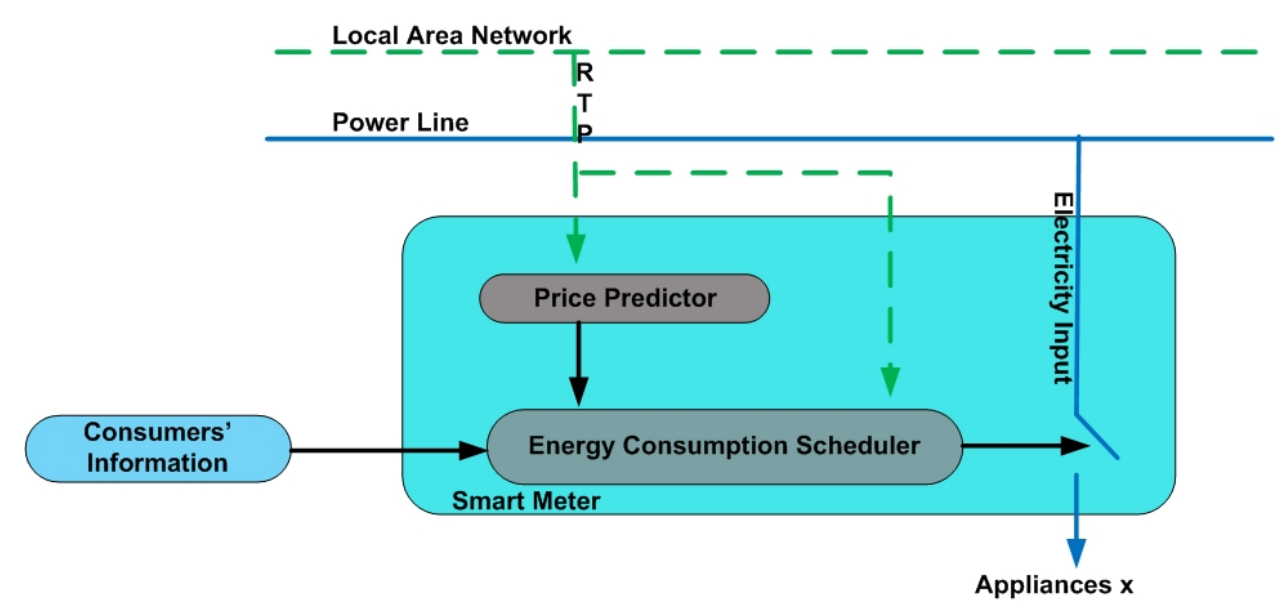

Figure 6. Price predictor and ECS device.

DSM Based on Home Energy Management System

Various home energy management systems (HEMS) have been designed to manage the consumer demand. These HEMS are further classified into two types: hardware-based HEMS and softwarebased HEMS.

\section{(i) Hardware-Based HEMS}

There are plenty of research articles in which the authors designed and proposed hardwarebased HEMS. These HEMS are based on different communication schemes, such as power line communication [124,125] and ZigBee [90,126]. The authors in [124] suggested a power line communication-based HEMS that can provide information on home energy consumption in real-time. In addition, it has the capability to make an intelligent plan for appliance control as well as optimizing power consumption at home. The HEMS consists of three modules: an advanced power control planning engine, a device control module, and a power resource management server. In [126], the authors explored a smart home energy management (SHEM) system based on the ZigBee sensor network. The authors divided the SHEM into various home networks, where each network consists of sensor nodes. Each and every home network performs different tasks by collecting the information through sensors, and on the basis of this information, it controls various home appliances. The information may be humidity, temperature, light and/or other phenomena, i.e., human movement, gas leakage, etc. Furthermore, the authors added a routing protocol named the disjoint multi-path based routing (DMPR) protocol. Using DMPR, the sensor nodes establish a wireless network with other sensors nodes and with the help of this network, it can intelligently control the system's services.

Similarly, in [90], the authors explained another ZigBee network-based HEMS. This scheme is used for residential demand response application and for the reduction of overall energy consumption. The proposed HEMS consists of a HEM unit which provides monitoring and control for the consumers and a load controller that is used to collect the consumption of data from different home appliances with the help of instructions from the HEM unit. The HEM unit consists of an embedded PC that runs a GUI software application and HEM communication module. The function of the embedded PC running the GUI software application is to switch on/off the consumer appliances on the basis of a demand response algorithm while the communication module establishes a communication network between the HEM unit and load controller. On the other side, the load controller provides an interface between the appliances and the HEM unit. The proposed system is used to monitor and control consumers' actual loads according to the demand responses in order to minimize the overall energy consumption. In [127], the authors introduced HEMS, in which the energy used by the various home appliances of consumers is compared with a reference energy level at the energy portal server. The reference energy and prices at the energy portal are periodically updated according to the instructions provided by the supplier. The HEMS compares the consumers' consumption of 
different appliances to that reference, and if the consumption exceeds the reference, the HEMS shifts the appliances into an efficient time slot where the price per $\mathrm{kWh}$ is low.

(ii) Optimization-Based or Software-Based HEMS

In software-based HEMS, the system consists of a framework that has the capability to schedule and manage the load at consumers' premises and also provide benefits to the consumers. These frameworks are based on different optimization algorithms, as shown in Figure 5. In [92], the authors suggested an in-home energy management system (iHEM) and optimization-based residential energy management (OREM) to reduce the energy cost and demand during peak hours. In addition, the iHEM system minimizes the consumers' bills and reduces their contribution to the peak load. The aforementioned schemes, i.e., iHEM, and OREM, are used to schedule and control the in-home appliances. The performance of the proposed OREM system has been compared with hardware-based HEMS and it was concluded that OREM outperforms hardware-based HEMS. The authors in $[93,128]$ proposed an efficient scheme for scheduling the consumers' energy consumption in a dynamic pricing environment. The proposed framework in [93] is based on mixed-integer linear programming (MILP) with the objective of developing a home energy controller and reducing the energy cost. The home energy controller controls different household energy appliances. With the help of this framework, PAPR can be reduced.

The authors in [94], investigated an intelligent HEM algorithm to manage the energy consumption of high power rating household appliances. In addition, it ensures that the base/critical load is supplied at all times. In this HEM algorithm, the total consumption of each consumer is kept below a certain threshold $(\mathrm{kW})$ where the threshold is updated regularly after one hour. Moreover, the authors presented a load scheduler to optimize the energy consumption of the consumers for dynamic price per $\mathrm{kWh}$. According to this scheduler, the consumers schedule their household appliances in an efficient way in order to get a reward from the suppliers and to reduce their electricity bills.

In [113], the authors used MILP and a heuristic approach to design a household energy management system. This household energy management system uses an eBox architecture that consists of a control logic unit (CLU) and an optimization module (OM). The CLU controls the overall system while the OM is responsible for selecting an optimal schedule on the basis of MILP and heuristic approach. The CLU collects signals from the consumer shiftable appliances or from the sensors deployed in the vicinity of these appliances and then dictates the OM to commence the optimization process and select an efficient schedule to reduce the energy consumption. The OM then communicates this efficient schedule to the CLU where the CLU implements it on the high power rating appliances. The high power rating appliances considered in this paper include water heaters, clothes dryers, cooling units, etc.

Conclusions of the subsection: In this subsection, we discussed the various types of DSM which consist of direct load reduction and load scheduling. Direct load reduction was further classified into two groups, i.e., energy efficient appliances and energy efficient building. Similarly, the load scheduling was divided into two categories, i.e., centralized and decentralized DSM schemes. Moreover, we categorized the load scheduling into three subparts which included DSM based on energy pricing, DSM based on energy consumption scheduling (ECS), and DSM based on home energy management (HEM). In addition, we also categorized DSM into two categories on the basis of the optimization type used in DSM modeling and the solution methodologies used in the model solution. We also summarized the available performance metrics and provided a detailed review of the literature from an optimization perspective as well as from an energy pricing perspective and tabulated it in Tables 6-8 respectively.

We identified some of the areas which need research attention. These areas include EeA, EeB, and the collective attainment of performance metrics. In the literature, very little work has been done on EeA and EeB; therefore, these types of DSM need further elaboration. Similarly, from Table 6, we can say that, in the literature, a unified framework with all the performance metrics mentioned in Table 6 
collectively achieved is missing. Therefore, a unified framework needs to be modelled where all the performance metrics regarding DSM are achieved.

\subsection{Cost Minimization by Employing Efficient DSM Schemes}

Cost minimization is the primitive and paramount parameter among DSM objectives. From the consumer perspective, it is the most influential parameter. In general, the production costs are very important. These costs are interlinked with the consumers' demands. As the consumers' demands increase, the production costs also increase. Especially in peak hours, the generation cost is very high, because in peak hours, the generation companies switch on their peaker power plants which, in turn, increases the generation cost. The cost minimization indirectly minimizes the demand during peak hours as well as PAPR and consumers' bills. Most researchers are engrossed in developing efficient algorithms to minimize the generation costs, either directly or indirectly. In the literature, various approaches have been utilized to develop efficient algorithms in order to minimize the electricity costs $[82,108,116,129-139]$. These approaches include the game theoretic approach, different pricing approaches, etc.

\subsubsection{Game Theoretic and Real-Time Pricing Approaches in Cost Minimization}

Cost minimization can be achieved by utilizing the various approaches mentioned in the literature. The game theoretic and real-time pricing approaches are the most prominent approaches available in the literature and are presented in the following text.

\section{Cost Minimization Using the Game Theoretic Approach}

Game theory is one of the mathematical tools used in the literature to model different DSM schemes that is valuable both for consumers as well as for suppliers. In $[61,81,82,140-143]$, the authors introduced autonomous DSM schemes based on game theory. In the first one of these articles, the authors proposed a scheme in which each consumer schedules his/her own energy usage in a time slot with a low price by participating in the game, thus reducing his/her electricity bills. The energy cost is minimized by achieving the Nash equilibrium point. The PAPR is reduced by using the distributed DSM in [61]. The formulation is based on the non-cooperative game theory, where the consumers act as players and the utility companies as strategies. Similarly, the authors in [140-142], used the multiple leader multiple follower Stackelberg game to maximize the profits of the micro-grid. In [81], the authors considered a scenario with multiple suppliers connected to a central DSM center as well as with the consumers through the communication link and power line, as shown in Figure 7.

Each of the suppliers has to submit a bid to the DSM center through the communication link, where the DSM center calculates the electricity price on the basis of these bids and on the information provided by the consumers in terms of an aggregated load.

The proposed framework is based on the non-cooperative game theory. The objective of the framework is to maximize the supplier's profit as well as to maximize the consumers' satisfaction in terms of bill reductions. The mathematical formulation is done for the supplier and consumer sides independently and is given as follows.

$$
\max \text { profit }=S_{j, t}\left(b_{t}, Q_{t}\right) \operatorname{Pe}\left(b_{t}, Q_{t}\right)-C_{j}\left(S_{j, t}\left(b_{t}, Q_{t}\right)\right)
$$

where $S_{j, t}($.$) is the generated electricity by the j$ th supplier at time $t$, which is a function of the bid vector of all suppliers and the aggregated load of consumers. $\mathrm{Pe}\left(b_{t}, Q_{t}\right)$ is the electricity price calculated by the DSM center, and $C($.$) is the generated electricity cost. On the consumer side, the problem is$ formulated as

$$
\max \sum_{t \in T}\left(U_{i}\left(L_{i}^{s h}(t)+L_{i}^{b}(t)\right)-\left(L_{i}^{s h}(t)+L_{i}^{b}(t)\right)\right) \frac{\sum_{i \in N}\left(L_{i}^{s h}(t)+L_{i}^{b}(t)\right)}{\sum_{r \in S} b_{r, t}}
$$


where $U_{i}($.$) represents the utility function for consumer i$ which shows the satisfaction of consumer $i$ with their electricity consumption. The utility is a function of the consumers' shiftable and base loads represented by $L_{i}^{s h}(t)$ and $L_{i}^{b}(t)$. In Equation (2), $N$ is the total number of consumers and $T$ is total number of time slots.

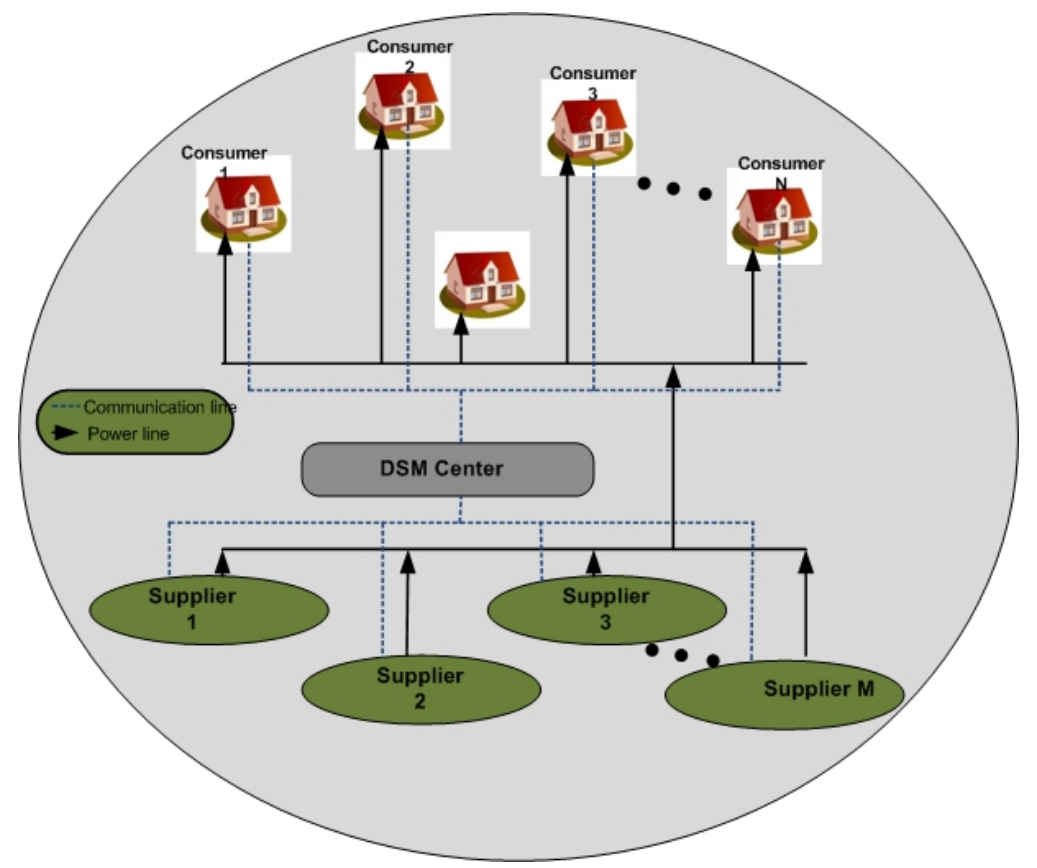

Figure 7. Game theory-based DSM scheme.

Similarly, in [77], Ding Li suggested an auction game-based algorithm to schedule consumer energy consumption. In this paper, the authors solved the problem of cost minimization in two different scenarios; the first one was the minimization of the utility cost of generation, and the second one was the maximization of consumer welfare. The authors achieved their objectives by first dividing the consumers' load into flexible and essential loads and then minimizing the flexible load for different intervals of time.

In [117] presented a profit maximization problem based on risk constrained demand responses. The proposed framework is composed of a micro-grid aggregator and a schedular, where the aggregator procures electricity from different sources and sells it to the consumers. The schedular in the proposed framework offers different scheduling contracts to the consumers in order to minimize the consumers' bills and to reduce the demand on the micro-grid during peak hours. The consumers have the choice of whether to sign the contract or not. If the consumers agree with the schedular contracts, then they are rewarded in two different ways, i.e., either the aggregator will serve the consumers with electricity consumption at a lower price or they will be awarded an extra amount of energy during off-peak hours. An evolutionary algorithm based on day ahead DSM was proposed by the author of [118]. The objective of the proposed framework is to shave the demand during peak hours and to minimize the generation cost.

\section{Cost Minimization Using DSM Scheme Based on RTP}

Generally, consumer demand is higher and more critical in peak hours. In order to ensure the supply of energy to the consumers in peak hours, the utility and generation companies run peaker power plants, and therefore, charge higher prices per $\mathrm{kWh}$ to the consumers. Moreover, by operating the peaker power plants, the peak to average power ratio (PAPR) increases, which, in turn, affects the reliability of the energy supply. Each consumer's electricity price is based on his/her load and the increase in the demanded load can lead to an increased electricity price. To manage the consumer 
demand, there are a lot of research articles that are based on real-time pricing with the objective of minimizing the electricity cost. In [98], the authors presented a DSM scheme consisting of an efficient scheduling model based on real-time pricing (RTP). The central controller installed at consumer's premises gets the RTP from the supplier end and schedules or shifts the high energy household devices through the home gateway into off-peak hours. The proposed model reduces the energy cost as well as the PAPR which leads to system stability. In [99], the authors explored an incentive-based demand response algorithm to shave the demand during peak hours. The proposed algorithm can be applied both for essential and flexible consumer loads. Furthermore, the scheme is divided into two control levels, i.e., the first control level is used to manage and improve the feeder voltage profile within a certain range and the second control level is used to minimize the peak demand and prevent the transformer from overloading. The proposed scheme minimizes consumers the demand during peak hours and considers the consumers' priorities and satisfaction and also improves the feeder voltage profile. A day ahead scheduling algorithm was provided by the authors of $[144,145]$ in order to minimize the energy costs.

A DSM scheme based on mixed integer multi-time scale stochastic optimization was proposed by Zhe Yu et al. in [119]. In this framework, the authors first considered the consumer's satisfaction by maximizing the power production, and then focused on energy consumption and cost of energy consumed and finally, suggested an efficient control strategy to minimize the peak demand.

The authors of [43] designed an autonomous DSM scheme to minimize the energy cost. The authors used game theory to formulate the consumption scheduling game with the following objective:

$$
\min \sum_{t=1}^{T} C_{t}\left(\sum_{n \in N} \sum_{a \in A_{n}} X_{n, a}^{t}\right)
$$

where $C_{t}\left(\sum_{n \in N} \sum_{a \in A_{n}} X_{n, a}^{t}\right)$ is the cost function and $X_{n, a}^{t}$ is the energy consumed by appliance $a$ of consumer $n$ at time $t$ hours. In addition, the authors in [75] minimized the demand during peak hours by shifting the high power rating appliances to off-peak hours that resulted in the minimization of PAPR. The PAPR minimization problem was formulated as follows:

$$
\min _{X_{n, i} \in \chi_{n}} \frac{\max \left(\sum_{n \in N} \sum_{a \in A_{n}} X_{n, a}^{t}\right)}{\frac{1}{T}\left(\sum_{n \in N} \sum_{a \in A_{n}} X_{n, a}^{t}\right)}
$$

where $\max \left(\sum_{n \in N} \sum_{a \in A_{n}} X_{n, a}^{t}\right)$ is the demand during peak hours and $\frac{1}{T}\left(\sum_{n \in N} \sum_{a \in A_{n}} X_{n, a}^{t}\right)$ is the average demand of consumer $n$. By solving Equation (4), the demand during peak hours is minimized which results in a flattened demand curve and hence, minimizes the deviation from the grid available load. As we mentioned earlier, in peak hours, the consumers are charged a higher price per unit because of the operating of the peaker power plants to fulfill the consumers' demands. If the load during peak hours is reduced or the high power rating appliances are re-scheduled to off-peak hours, the generation companies will not need to operate additional plants and hence, the cost of generation and the consumers' bills will be minimized.

In [91], the authors proposed a framework based on fairness in billing and consumer privacy. According to this framework, an autonomous DSM can work efficiently if the number of consumers contributing to the DSM is increased which can be achieved via coordination and communication among consumers through smart meters. Moreover, to motivate the consumers to participate in the proposed scheme, it is important to devise a fair billing algorithm in the form of incentives for the consumers.

Conclusions of the subsection: In this subsection, we focused on key performance metrics, i.e., cost minimization. We call them key performance metrics because once the cost is minimized, then most of the other performance metrics are automatically attained. We provided a detailed review of literature from a cost minimization perspective. We divided this cost minimization survey into two 
subsections i.e., cost minimization using the game theoretic approach and cost minimization using DSM schemes based on RTP.

From this subsection, we also identified an open research area including consumer participation in the given DSM, consumer privacy, consumer satisfaction and the implementation complexity of the given DSM model. Therefore, in addition to cost minimization, it is mandatory to converge the attention of researchers towards DSM schemes which can educate the consumers regarding the given DSM to participate in; also, it is crucial to take care of consumer privacy and satisfaction. Moreover, the proposed model needs to be cost-effective and simple to implement.

\section{Integration of DERs into the Main Grid and How It Helps to Achieve the Various Performance Metrics of the DSM}

In the traditional power system, most of the electricity production is centralized and is generated through fossil fuel. This centralized energy generation produces plenty of NOx and SOx that is polluting the environment. Besides this, electricity generation using fossil fuels is becoming more expensive day by day due to the increased cost of fossil fuel. Therefore, the organization of environmental protection as well as the high production cost of electricity has forced various government agencies to rethink their energy production resources $[35,146]$. The centralized generation of power is not only costly and inefficient, but it is also sometimes not enough to meet the consumers' demands during peak hours [147]. To mitigate this issue, the use of distributed energy resources (DERs) is one of the solutions [148]. DERs can be divided into two different types: DERs with non-renewable sources of energy and DERs with renewable energy sources.

(i) DERs with Non-Renewable Sources of Energy

This type of DER includes diesel generators, gas engine generators, etc. In this case, the DERs generate the energy by using small-sized gas engine generators and diesel generators, but it is not an economical source of generation.

(ii) DERs with Renewable Energy Sources

In this type of DER consists of renewable energy resources, i.e., photovoltaic (PV) cells, wind turbines, small hydel power plants and battery banks for storing the generated energy. Renewable sources of energy are cheaper and green sources of energy [149]. Renewable sources have enough advantages over the diesel and gas generators; however, there are some problems with these sources. The advantages and challenges associated with DERs sources are encapsulated in Table 9.

Table 9. Advantages and challenges of DERs (renewable).

\begin{tabular}{ccc}
\hline Type of Renewable DERs & Advantages & Challenges \\
\hline & Infinite source of energy & Variable output because wind speed is not constant [150] \\
Wind Turbines [151,152] & Easy to install & Uncertainty \\
& No maintenance & Turbines are very noisy \\
& No running charges & \\
\hline PV Cells $[151,154]$ & Easy to install & Large area required for installation [153] \\
& Low maintenance & Inefficient on cloudy and rainy days \\
\hline
\end{tabular}

In this section, we discussed DERs and the integration and role of DERs in cost minimization and PAPR minimization. Moreover, we also discussed the unpredictable nature of DERs and their impacts on DSM.

\subsection{Integration of DERs}

According to the international energy agency survey, researchers are working to determine how best to produce electricity by the use of DERs. According to this survey, from 2010 to 2035, the production tree of DERs in the form of hydel, wind and solar will change by up to $50 \%, 25 \%$, 
and $7.5 \%$, respectively. The production of electricity from these DERs is not only unreliable, but its integration into the main grid is a problematic task. Therefore, the integration of DERs into the main grid is the most challenging and conspicuous research topic. Researchers are trying to discover new and improved schemes for its integration. Some of these schemes were given in [155-157]. The uncertain and inconsistent nature of DERs can affect the reliability and stability of the power supply. To overcome this issue, different complementary solutions were suggested in [79,158-161]. DERs are normally installed at consumers' premises that are equally accessible for both consumers and the distributed grid. In cases of high demand from the consumer side, these DERs help the grid to fulfill the high demand in peak hours [162,163]. A game theoretic-based DSM scheme for consumers with DERs was proposed by the authors in [115]. In this scheme, there are two games, i.e., the non-cooperative game and the Stackelberg game. The first type is played among the consumers while the second one is played between the consumer and the supplier. The authors minimized the cost function of consumers by selling the surplus power through the non-cooperative game to the suppliers.

\subsection{PAPR Minimization Using DERs}

Most researchers are working on how to efficiently harmonize the DERs with the main grid station. Assimilations of DERs can reduce the demand during peak hours and the PAPR. By using DERs, consumer demand can be managed efficiently. The US Department of Energy arranged different conferences and workshops in 2001 in order to elaborate the integration of DERs into the main grid [164] which could help to minimize PAPR. For efficient integration of the DERs into the main grid, the authors in [165], explored a scheme for a reliable communication network. According to the authors, this network ensures that the energy generated by DERs is fed into the main grid efficiently and can help to manage and curtail consumers' demands during peak hours.

\subsection{Role of DERs in Cost Minimization}

DERs play an important role in cost minimization. In the literature, various articles are available where the benefits of DERs in terms of cost minimization have been explored. We have summarized all the DSM schemes where the authors used DERs as a cost minimization source in Table 8 . The authors in [64], minimized the generation cost by developing a control algorithm known as the "Lyapunov-based cost minimization algorithm". The authors considered that each consumer has their own DER, storage devices, and an essential and flexible load. Furthermore, the consumers have coordinating control entity for the minimization of the generation cost. Another cost minimization technique was suggested by the author in [79], in which the consumers' costs are minimized by the use of DERs. The authors divided the consumers' load into two different parts, i.e., essential and flexible loads. Moreover, through the use of DERs, the authors employed the Lyapunov optimization solution in order to fill the gap between consumption and production.

Similarly, the authors in $[69-73,166,167]$ suggested distributed generation with the concept of the virtual power player (VPP) to manage the DERs. Moreover, the authors in [167] provided the concept of generation cost minimization using VPP. The authors in [95], analyzed a modified particle swarm optimization technique to integrate the DERs into the main grid and to minimize the cost of the VPP that manages the DERs. With this technique, the cost of VPP is minimized by using the mixed-integer non-linear optimization technique. The generation cost and the energy taken from the main grid are both minimized by efficiently applying the proposed schedule according to the demand response. The consumer demand is managed in three different steps where these steps are named $\operatorname{Red}_{A}, \operatorname{Red}_{B}$, and $\operatorname{Red}$. The main objective of the authors was to minimize the generation cost of electricity. The mathematical formulation of [95] is given by (5). 


$$
\begin{aligned}
\min & C=\sum_{t=1}^{T}\left(\sum _ { D G = 1 } ^ { N _ { D G } } \left(C_{A(D G, t)} X_{D G(D G, t)}+C_{B(D G, t)} P_{D G(D G, t)}+C_{C(D G, t)} P_{D G(D G, t)}^{2}\right.\right. \\
& \left.+C_{E A P(D G, t)} P_{E A P(D G, t)}\right)+\sum_{S P=1}^{N_{S P}}\left(C_{S P(S P, t)} P_{S P(S P, t)}\right)+\sum_{L=1}^{N_{L}}\left(C_{R E D \_A(L, t)}\right. \\
& P_{R E D \_A(L, t)}+C_{R E D \_B(L, t)} P_{R E D \_B(L, t)}+C_{R E D \_C(L, t)} P_{R E D \_C(L, t)}+P_{N S D(L, t)} \\
& \left.\left.C_{N S D(L, t)}\right)+\sum_{S=1}^{N_{S}}\left(C_{D c h(S, t)} P_{D c h(S, t)}-C_{C h(S, t)} P_{C h(S, t)}\right)\right)
\end{aligned}
$$

where $C_{A(D G, t)}, C_{B(D G, t)}$, and $C_{C(D G, t)}$ represent the fixed, linear, and quadratic costs coefficient of the generator units in time $t$, respectively, while $C_{C h(S, t)}$ and $C_{D c h(S, t)}$ is the charging and discharging costs of battery $S$ in time $t$, respectively. The minimization problem is formulated in three different steps where each step has an associated operating cost which is represented by $C_{R E D_{-} A(L, t)}, C_{R E D_{-} B(L, t)}$ and $C_{R E D_{-} C(L, t)}$ to schedule load $L$ in time $t$. The cost coefficient for the excess available power at diesel generator $(\mathrm{DG})$ is represented by $C_{E A P(D G, t)}$. The cost for the non-supplied or surplus power is expressed by $C_{N S D(L, t)}$. While $P_{D G(D G, t)}, P_{C h(S, t)}$, and $P_{D c h(S, t)}$ represent the active power of DG and the active charging and discharging power loads of storage $S$. $P_{R E D_{-} A(L, t)}, P_{R E D \_B(L, t)}$, and $P_{R E D \_C(L, t)}$ are the amounts of power reduction by steps $\operatorname{Red}_{A}, \operatorname{Red}_{B}$, and $\operatorname{Red}_{C}$, for load $L$. Furthermore, the excess generated power by DG and resupplied demand for load $L$ is represented by $P_{E A P(D G, t)}$ and $P_{N S D(L, t)}$. $P_{S P(S P, t)}$ is amount of active power acquired from the supplier at time $t . N_{L}, N_{S}$, and $N_{S P}$ are the load, number of storage devices and number of external suppliers, respectively.

The authors in [84] used another DSM scheme with the objective to flatten the demand curve. The authors first divided the consumer's load into two different types: the essential load and the flexible load. Then, they formulated the optimization problem for the essential load of $N$ consumers. According to the authors, the total essential load of all $N$ consumers at time slot $t$, can be computed as

$$
E(t)=\sum_{n=1}^{N} E_{k}(t)
$$

The energy consumption of all $N$ consumers should not exceed the threshold $\gamma_{N}^{\max }$, (i.e., $E(t) \leq \gamma_{N}^{\max }$ ), where $\gamma_{N}^{\max }$ is the maximum power generated by all the $N$ consumers through DERs. Beside the essential load, each consumer has his/her own flexible load, where the flexible load is scheduled in three different scenarios, i.e., delayed scheduling, advanced scheduling, and fully flexible in both direction-either delayed or advanced.

\subsection{Unpredictable Nature of DERs and the Impact on DSM}

Due to the unpredictable and uncertain nature of renewable DERs, the efficiency of the DSM scheme can be affected. While developing a DSM scheme, the unpredictability and uncertainty associated with DERs should be considered. In [87], the authors investigated a dynamic energy management system for the future smart grid by considering unpredictable renewable distributed energy resources, consumer demand, and energy storage devices. In this work, the authors considered two type of demanded load, i.e., mandatory load and flexible load, with the objective of minimizing the overall cost of the consumed energy. The cost of energy was minimized as follows:

$$
\min \lim _{T \rightarrow \infty} \frac{1}{T} \sum_{t=0}^{T-1} E\{U(t)\}
$$

where $U(t)$ is a function of the energy consumed at time $t$ and is given by $U(t)=f(N(t))$. The variable $N(t)$ is the amount of electricity that would be generated by the supplier to fulfill the consumer load which is calculated from 


$$
N(t)=P(t)-R(t)
$$

where $P(t)$ represents the consumer's load at time $t$, and $R(t)$ denotes the renewable generated power. The authors further concluded that each user should have bi-directional communication with the utility company, and each consumer has his/her own DERs and storage device. Whenever the consumer has surplus power besides his/her own usage/mandatory load, then by the bi-directional communication can be sold to the main grid which could help to fulfil the demands during peak hours of other consumers [168]. In [112], the concept of DER coordination was explored. The authors used a particle swarm optimization (PSO) technique called CPSO-R to quantify a social welfare (which is a function of cost, PAPR, net benefits, etc.) added by the DERs coordination. With this technique, firstly, each DER is scheduled independently and then all DERS are scheduled collectively in order to find the above described social welfare. Then, on the basis of this value, the consumers schedule their consumption to maximize their net benefits. In this work, the authors presented a smart home case study in which, by applying the CPSO-R, the net benefit of the consumer was maximized by scheduling the controllable DERs according to the scheduling algorithm. In this particular case, it reduced the consumers' energy bills by $16 \%$ to $25 \%$.

In [97], the authors explored a day-ahead optimization based DSM scheme for consumers with DERs and storage devices. In addition, the authors considered consumers with greater consumption than production or storage. In that scenario, the consumers of this type import energy from the main grid to fulfill their required demands which, in turn, increases the load on the main grid. The proposed scheme reduces the consumption of these users in this scenario by using a game theoretical approach. Through the integration of DERs into the main grid, there is an imbalance in the grid. The authors in [74] considered an imbalanced condition and presented an energy management based on the novel pricing scheme to balance the uncertainty caused by the integration of DERs into the main grid. The novel pricing scheme was obtained by solving a convex linear inequality matrix.

In [78], the authors presented a solution for problems occurring during the integration of DERs into the main grid. In the proposed scheme, there is no need for supplier involvement. The DERs generated energy at the consumer premises is used by the consumer and the surplus energy is sold to the nearby needy consumers through by the existing distribution network. The proposed scheme is implemented in the Korean smart distribution management system and is used to minimize the losses of the distribution feeder and to maintain the system's reliability. Another DSM scheme for the displaceable residential load which uses a controller installed at the consumer premises was discussed in [114]. The controller is used for the minimization of the overall energy cost and to improve the reliability of the power system. To produce a reliable system and to flatten the load curve, the controller at each consumer's end is in contact with the neighbor consumers. The communication between neighbors is asynchronous and is based on distribution coordination scheme. The controller is operating on multi-objective optimization algorithm where the cost of consumers and the flattening of the load curve are formulated as follows:

$$
\begin{array}{r}
\min z_{c}=\sum_{t \in T} C^{t} P^{t} \triangle t, \\
\min z_{s}=\frac{\sum_{t \in T} S^{t} P^{t} \triangle t}{T}
\end{array}
$$

where $z_{c}$ is considered the primary objective variable which represents the energy cost at time $t$, while $z_{s}$ denotes the load curve function which is considered the secondary objective. $P^{t}$ is the power consumed by consumers for interval $\triangle t$ with expenses of $C^{t}$, and $S^{t}$ represents the aggregated load that can be computed by the interaction of the neighbors through a controller installed at their premises. Equation (10) is also named the load stability objective equation.

Another scheduling model was discussed by the authors of [96], where the consumers' energy consumption was divided into two different parts: deterministic dynamic consumption and stochastic 
consumption. The authors maximized the DER generation by an formulating energy scheduling problem using Gaussian approximation and the rolling horizon optimization technique. The authors in [88] presented another home energy management system in which storage devices are installed at the consumer's premises. The storage devices are jointly accessible for both suppliers and for consumers. Therefore, the proposed system is beneficial both for suppliers as well as for consumers. The consumers can reduce their energy bills by shifting the peak demand to off-peak hours, where they are charged a low price per $\mathrm{kWh}$ which minimize the demand during peak hours. Moreover, due to the reduction in demand during peak hours, the generation cost is also minimized.

Conclusions of the section: In this section, we introduced the DERs, the integration of DERs, PAPR minimization using DERs, cost minimization using DERs, and the unpredictable nature of DERs. Moreover, we also discussed that how these DERs can help in achieving various performance metrics of the given DSM model like PAPR and cost minimization. In addition, we also summarized the unpredictable nature of DERs and their impacts on the DSM schemes.

In this section, we summarized that DERs can help the DSM model in cost minimization and PAPR reduction very efficiently, but due to the uncertain nature of DERs, it can not continuously help the DSM model. Therefore, we identified that DER availability forecasting and frequent adjustment of the DSM model according to the uncertainty associated with DERs need to be considered in the upcoming DSM models. Moreover, attention is needed to motivate the consumers to increase the installed DERs and also to discover various methods for the optimal placement of DERs which would result in the minimization of line losses.

\section{Future Research Directions}

Based on the above survey, we concluded that we can focus on various limitations and challenges that arise during the design and implementation of DSM schemes and integration of DERs. For an efficient, robust, and economical DSM scheme along with DERs, these limitations should be addressed. These limitations and challenges are categorized into two subgroups: DSM based open research direction and DERs based open research direction. These limitations include guaranteeing the reliability of the power system and communication networks used in DSM as well as the security and privacy of consumers, load profile modeling, consumers' participation in the DSM scheme, catering for consumers' preferences and priorities, maximization of DER usage, optimal placement of DERs and educating the consumers about energy consumption.

\subsection{Open Research Direction for DSM}

\subsubsection{Reliability of the Power System and Communication Networks Used in DSM}

The reliability of the power system and the reliability of the communication media used in the DSM schemes are imperative and indispensable parts of smart grid technology. The reliability of the power system mainly depends on the consumers' demands, i.e., a system will be reliable if the total consumption of all consumers is under the threshold provided by the supplier. If the demanded load exceeds the threshold level, then the whole system will go down. Owing to this, it is mandatory to consider the power system's reliability during the design and development of the stages of an efficient DSM scheme. Advance load forecasting techniques can be used to improve the reliability of the power system. Similarly, the communication links used for energy management are also of great importance. For a robust and reliable DSM scheme, the reliability of the communication networks is also as valuable as power system reliability. In future research, detailed consideration is needed for the reliability of the power system as well as that of the communication network along with consumers benefits.

\subsubsection{Security and Privacy}

The security and privacy of the consumers is the key aspect of an efficient DSM scheme. In DSM, there is a sharing of energy consumption information among the consumers. While designing a 
DSM scheme, secure information sharing among consumers needs to be considered. It is important to discover efficient novel DSM schemes where the consumers' privacy is considered. Moreover, robust and reliable communication needs to be developed for secure information sharing. Therefore, consumers' DSM schemes with security and privacy consideration can be a future research direction.

\subsubsection{Load Profile Modeling}

DSM is the art of managing consumers' load profilels. Demand during peak hours and increases in the electricity price are associated with the load profile. Moreover, system instability and the mismatch between generation and utilization are also dependent on the load profile. Therefore, modeling of the load profile is the key factor in DSM. While designing the DSM scheme, it is mandatory to model the load profile of each consumer before DSM scheme implementation. Therefore, the development of DSMs based on the load profile could be another research direction.

\subsubsection{Consumers' Participation in the Proposed DSM Scheme}

The participation of consumers in various DSM schemes plays a vital role. The more consumers participate in the scheduling algorithm, the les or the demand during peak hours will be, and also the more stable the system will be. In fact, as the stability of the power system is linked with the consumers' demanded load, consumers' participation in the proposed DSM can lead to a flattened demanded load curve which can help the main grid to remain stable. To motivate consumers to join the proposed schemes, multiple incentives can be given to the consumers. This area can be further elaborated, and research attention is needed to develop new incentive schemes to attract the consumers' concentration towards the proposed DSM schemes.

\subsubsection{Consumers' Preferences and Priorities}

Consumers preferences and priorities are the most important factors in DSM. The existing literature contains various DSM schemes which are cost-effective and can efficiently achieve their required objectives; however, the consumer's preferences and priorities are not considered in these schemes. As in DSM, the consumers' demands are managed at the consumers' premises; therefore, it is very important to care about the consumers' preferences and priorities. Therefore, the design of a DSM scheme based on consumers' preferences and priorities may be a new research direction.

\subsection{Open Research Direction for DERs}

\subsubsection{Maximization of DERs}

DERs, in the form of renewable energy, are important, green, and non-toxic sources of electricity generation. They are cheaper sources of electricity and can be installed at the consumer's premises in a distributed manner. With the distributed installation of these sources in the consumers' vicinity, the line losses that occur in energy transportation from the main grid can be significantly reduced. It is highly commendable to maximize the use of DERs in the form of renewable energy resources and to force the consumers through some incentive to install these sources on their premises. In DSM, the use of DERs can play an important role, especially in the reduction of the peak hour load and demand curve flattening. However, the integration of DERs into the main grid and dealing with the uncertainty and inconsistency of DERs are challenging issues. It is, therefore, needed for different integration techniques to be explored and also for different algorithms to be discovered for optimal placement of DERs in order to cover the aforementioned problems.

\subsubsection{Optimal Placement of DERs}

The optimal placement of DERs is very important for a given DSM. The placement of DERs plays an important role in loss minimization which can, in turn, improve the DSM schemes' efficiency. 


\subsubsection{Educating the Consumers}

Knowledge about home appliances and their energy consumption is very important for each and every consumer. All consumers want to reduce their electricity bills and also to improve their lifestyles. In current literature, there are various DSM schemes that are used for consumer electricity management; however, their implementation/installation at consumers' premises is not possible without educating the consumers about the energy consumption of various home appliances. It is needed for workshops and conferences to be arranged in order to guide the consumers regarding their electricity consumption.

\section{Conclusions}

This survey reviewed the smart grid and different energy management aspects of the smart grid. We reviewed the role of DSM in smart grid technology from which it can be concluded that without DSM, smart grid technology is incomplete. We reviewed various schemes and different approaches used to optimize and reform the energy consumption by utilizing different DSM techniques. We classified the DSM schemes available in the literature under various categories including direct load reduction, load scheduling, centralized DSM, decentralized DSM, DSM based on different pricing schemes, DSM based on ECS, DSM based on the HEM system, and DSM based on different optimization approaches. From all of the literature surveys, we deduced that an efficient DSM scheme can optimize the consumer energy consumption through six different perspectives, i.e., electricity bill reduction, social welfare maximization, peak hour demand reduction, generation cost minimization, demand curve flattening, and maximization of consumer satisfaction. Distributed energy resources along with centralized generation play vital roles in achieving the aforementioned objectives of DSM. In the literature, there are various schemes which are used to integrate these distributed generations into the main grid. We discussed the role of DERs in DSM and their impacts on consumers' energy consumption, and we also reviewed different integration techniques. We also outlined some future research directions in the context of DSM in the smart grid. These open research areas included the reliability of the power system and communication networks used in DSM, the security and privacy of consumers, load profile modeling, consumer participation in the DSM schemes, catering for consumers' preferences and priorities, the maximization of DER usage, optimal placement of DERs, and educating the consumers about energy consumption.

Author Contributions: S.A., A.A. and M.N. conceived the idea; The nomenclature of the paper was prepared jointly by S.A., A.A., M.N., W.E., and H.S.K.; Data for the review was collected by S.A., A.A., and M.N.; The in depth review was prepared by consultation with W.E. and H.S.K.; Finally, A.A., M.N., W.E., and H.S.K. reviewed, checked, corrected, and commented on the manuscript. The content of this survey consists of energy management solutions, performance metrics, and optimization objectives associated with energy management and role of the DERs.

Acknowledgments: This work is supported by BK21 Plus, the National Research Foundation of Korea (NRF) grant funded by the Korea government (MSIP) (2016R1A2B4008457).

Conflicts of Interest: The authors declare no conflict of interest.

\section{References}

1. Javaid, N.; Ullah, I.; Akbar, M.; Iqbal, Z.; Khan, F.A.; Alrajeh, N.; Alabed, M.S. An intelligent load management system with renewable energy integration for smart homes. IEEE Access 2017, 5, 13587-13600. [CrossRef]

2. Anderson, R.; Fuloria, S. Who Controls the off Switch? In Proceedings of the First IEEE International Conference on Smart Grid Communications (SmartGridComm), Gaithersburg, MD, USA, 4-6 October 2010; pp. 96-101. [CrossRef]

3. Malik, A.; Ali, Z.; Awan, A.B.; Abo-Khalil, A.G.; Sidhu, G.A.S. Achieving Cost Minimization and Fairness in Multi-Supplier Smart Grid Environment. Energies 2018, 11, 1367. [CrossRef] 
4. Fang, X.; Misra, S.; Xue, G.; Yang, D. Smart Grid, The New and Improved Power Grid: A Survey. IEEE Commun. Surv. Tutor. 2012, 14, 944-980. [CrossRef]

5. Amin, S.M.; Wollenberg, B.F. Toward a smart grid: Power delivery for the 21st century. IEEE Power Energy Mag. 2005, 3, 34-41. [CrossRef]

6. Zhang, P.; Li, F.; Bhatt, N. Next-Generation Monitoring, Analysis, and Control for the Future Smart Control Center. IEEE Trans. Smart Grid 2010, 1, 186-192. [CrossRef]

7. Rebollo-Monedero, D.; Bartoli, A.; Hernández-Serrano, J.; Forn, J.; Soriano, M. Reconciling privacy and efficient utility management in smart cities. Trans. Emerg. Telecommun. Technol. 2014, 25, 94-108. [CrossRef]

8. Oliveira-De Jesus, D.; Rios, M.; Ramos, G.A. Energy Loss Allocation in Smart Distribution Systems with Electric Vehicle Integration. Energies 2018, 11, 1962. [CrossRef]

9. Zhao, C.; He, J.; Cheng, P.; Chen, J. Consensus-based energy management in smart grid with transmission losses and directed communication. IEEE Trans. Smart Grid 2017, 8, 2049-2061. [CrossRef]

10. Li, Q.; Zhou, M. The future-oriented grid-smart grid. J. Comput. 2011, 6, 98-105. [CrossRef]

11. Bose, A. Smart Transmission Grid Applications and Their Supporting Infrastructure. IEEE Trans. Smart Grid 2010, 1, 11-19. [CrossRef]

12. El Shafie, A.; Niyato, D.; Hamila, R.; Al-Dhahir, N. Impact of the Wireless Network's PHY Security and Reliability on Demand-Side Management Cost in the Smart Grid. IEEE Access 2017, 5, 5678-5689. [CrossRef]

13. Chakraborty, N.; Mondal, A.; Mondal, S. Intelligent scheduling of thermostatic devices for efficient energy management in smart grid. IEEE Trans. Ind. Inform. 2017, 13, 2899-2910. [CrossRef]

14. Baumeister, T. Literature Review on Smart Grid Cyber Security; Collaborative Software Development Laboratory at the University of Hawaii: Honolulu, HI, USA, 2010.

15. Brown, H.E.; Suryanarayanan, S. A survey seeking a definition of a smart distribution system. In Proceedings of the North American Power Symposium (NAPS), Starkville, MS, USA, 4-6 October 2009; pp. 1-7. [CrossRef]

16. Chen, S.Y.; Song, S.F.; Li, L.; Shen, J. Survey on Smart Grid Technology. Power Syst. Technol. 2009, 33, 1-7.

17. Hassan, R.; Radman, G. Survey on Smart Grid. In Proceedings of the IEEE Southeast Con (SoutheastCon), Concord, NC, USA, 18-21 March 2010; pp. 210-213. [CrossRef]

18. Rohjans, S.; Uslar, M.; Bleiker, R.; Gonzaalez, J.; Specht, M.; Suding, T.; Weidelt, T. Survey of Smart Grid Standardization Studies and Recommendations. In Proceedings of the First IEEE International Conference on Smart Grid Communications (SmartGridComm), Gaithersburg, MD, USA, 4-6 October 2010; pp. 583-588. [CrossRef]

19. Uslar, M.; Rohjans, S.; Bleiker, R.; Gonzalez, J.; Specht, M.; Suding, T.; Weidelt, T. Survey of smart grid standardization studies and recommendations part 2. In Proceedings of the IEEE PES Innovative Smart Grid Technologies Conference Europe (ISGT Europe), Gothenberg, Sweden, 11-13 October 2010; pp. 1-6.

20. Yu, Y.; Luan, W. Smart grid and its implementations. Proc. CSEE 2009, 29, 1-8.

21. Gungor, V.C.; Lambert, F.C. A survey on communication networks for electric system automation. Comput. Netw. 2006, 50, 877-897. [CrossRef]

22. Wang, W.; Xu, Y.; Khanna, M. A survey on the communication architectures in smart grid. Comput. Netw. 2011, 55, 3604-3629. [CrossRef]

23. Akyol, B.; Kirkham, H.; Clements, S.; Hadley, M. A Survey of Wireless Communications for the Electric Power System; Prepared for the US Department of Energy; Pacific Northwest National Laboratory (PNNL): Richland, WA, USA, 2010.

24. Chen, T.M. Survey of cyber security issues in smart grids. In SPIE Defense, Security, and Sensing; International Society for Optics and Photonics: Bellingham, WA, USA, 2010; p. 77090D.

25. Vasconcelos, J. Survey of Regulatory and Technological Developments Concerning Smart Metering in the European Union Electricity Market; Robert Schuman Centre for Advanced Studies PP: Florence, Italy, 2008.

26. Vardakas, J.; Zorba, N.; Verikoukis, C. A Survey on Demand Response Programs in Smart Grids: Pricing Methods and Optimization Algorithms. IEEE Commun. Surv. Tutor. 2015, 17, 152-178. [CrossRef]

27. Gungor, V.C.; Sahin, D.; Kocak, T.; Ergut, S.; Buccella, C.; Cecati, C.; Hancke, G.P. A survey on Smart Grid Potential Applications and Communication Requirements. IEEE Trans. Ind. Inform. 2013, 9, 28-42. [CrossRef]

28. Sabbah, A.I.; El-Mougy, A.; Ibnkahla, M. A survey of networking challenges and routing protocols in smart grids. IEEE Trans. Ind. Inform. 2014, 10, 210-221. [CrossRef] 
29. Yan, Y.; Qian, Y.; Sharif, H.; Tipper, D. A survey on cyber security for smart grid communications. IEEE Commun. Surv. Tutor. 2012, 14, 998-1010. [CrossRef]

30. Erol-Kantarci, M.; Mouftah, H. Energy-Efficient Information and Communication Infrastructures in the Smart Grid: A Survey on Interactions and Open Issues. IEEE Commun. Surv. Tutor. 2015, 17, 179-197. [CrossRef]

31. Espe, E.; Potdar, V.; Chang, E. Prosumer Communities and Relationships in Smart Grids: A Literature Review, Evolution and Future Directions. Energies 2018, 11, 2528. [CrossRef]

32. Reka, S.S.; Dragicevic, T. Future effectual role of energy delivery: A comprehensive review of Internet of Things and smart grid. Renew. Sustain. Energy Rev. 2018, 91, 90-108. [CrossRef]

33. Kakran, S.; Chanana, S. Smart operations of smart grids integrated with distributed generation: A review. Renew. Sustain. Energy Rev. 2018, 81, 524-535. [CrossRef]

34. Meyabadi, A.F.; Deihimi, M. A review of demand-side management: Reconsidering theoretical framework. Renew. Sustain. Energy Rev. 2017, 80, 367-379. [CrossRef]

35. Ghiani, E.; Serpi, A.; Pilloni, V.; Sias, G.; Simone, M.; Marcialis, G.; Armano, G.; Pegoraro, P.A. Multidisciplinary Approach for the Development of Smart Distribution Networks. Energies 2018, 11, 2530. [CrossRef]

36. Zafar, R.; Mahmood, A.; Razzaq, S.; Ali, W.; Naeem, U.; Shehzad, K. Prosumer based energy management and sharing in smart grid. Renew. Sustain. Energy Rev. 2018, 82 Pt 1, 1675-1684. [CrossRef]

37. Zame, K.K.; Brehm, C.A.; Nitica, A.T.; Richard, C.L.; Schweitzer, G.D., III. Smart grid and energy storage: Policy recommendations. Renew. Sustain. Energy Rev. 2018, 82 Pt 1, 1646-1654. [CrossRef]

38. Bharothu, J.N.; Sridhar, M.; Rao, R.S. A literature survey report on Smart Grid technologies. In Proceedings of the International Conference on Smart Electric Grid (ISEG), Guntur, India, 19-20 September 2014; pp. 1-8.

39. Farhangi, H. The path of the smart grid. IEEE Power Energy Mag. 2010, 8, 18-28. [CrossRef]

40. Gharavi, H.; Ghafurian, R. Smart grid: The electric energy system of the future. Proc. IEEE 2011, 99, 917-921. [CrossRef]

41. Grilo, A.; Sarmento, H.; Nunes, M.; Gonçalves, J.; Pereira, P.; Casaca, A.; Fortunato, C. A wireless sensors suite for smart grid applications. In Proceedings of the First International Workshop on Information Technology for Energy Applications (IT4ENERGY 2012), Lisbon, Portugal, 6-7 September 2012.

42. Gungor, V.; Lu, B.; Hancke, G. Opportunities and Challenges of Wireless Sensor Networks in Smart Grid. IEEE Trans. Ind. Electron. 2010, 57, 3557-3564. [CrossRef]

43. Gellings, C. The concept of demand-side management for electric utilities. Proc. IEEE 1985, 73, 1468-1470. [CrossRef]

44. Carley, S. Energy demand-side management: New perspectives for a new era. J. Policy Anal. Manag. 2012, 31, 6-32. [CrossRef]

45. Bu, S.; Yu, F.; Liu, P. A game-theoretical decision-making scheme for electricity retailers in the smart grid with demand-side management. In Proceedings of the IEEE International Conference on Smart Grid Communications (SmartGridComm), Brussels, Belgium, 17-20 October 2011; pp. 387-391. [CrossRef]

46. Babu, C.A.; Ashok, S. Peak Load Management in Electrolytic Process Industries. IEEE Trans. Power Syst. 2008, 23, 399-405. [CrossRef]

47. Ramanathan, B.; Vittal, V. A Framework for Evaluation of Advanced Direct Load Control with Minimum Disruption. IEEE Trans. Power Syst. 2008, 23, 1681-1688. [CrossRef]

48. Chu, C.M.; Jong, T.L. A Novel Direct Air-Conditioning Load Control Method. IEEE Trans. Power Syst. 2008, 23, 1356-1363. [CrossRef]

49. Gellings, C.; Smith, W.M. Integrating demand-side management into utility planning. Proc. IEEE 1989, 77, 908-918. [CrossRef]

50. Imamura, A.; Yamamoto, S.; Tazoe, T.; Onda, H.; Takeshita, H.; Okamoto, S.; Yamanaka, N. Distributed demand scheduling method to reduce energy cost in smart grid. In Proceedings of the IEEE Region 10 Humanitarian Technology Conference (R10-HTC), Sendai, Japan, 26-29 August 2013; pp. 148-153. [CrossRef]

51. Exarchakos, L.; Leach, M.; Exarchakos, G. Modelling electricity storage systems management under the influence of demand-side management programmes. Int. J. Energy Res. 2009, 33, 62-76. [CrossRef]

52. Eissa, M. First time real time incentive demand response program in smart grid with i Energy management system with different resources. Appl. Energy 2018, 212, 607-621. [CrossRef] 
53. Li, D.; Chiu, W.Y.; Sun, H.; Poor, H.V. Multiobjective Optimization for Demand Side Management Program in Smart Grid. IEEE Trans. Ind. Inform. 2018, 14, 1482-1490. [CrossRef]

54. Pratt, R.G.; Balducci, P.; Gerkensmeyer, C.; Katipamula, S.; Kintner-Meyer, M.C.; Sanquist, T.F.; Schneider, K.P.; Secrets, T. The Smart Grid: An Estimation of the Energy and $\mathrm{CO}_{2}$ Benefits; Pacific Northwest National Laboratory: Washington, DC, USA, 2010; pp. 3-27.

55. Strbac, G. Demand side management: Benefits and challenges. Energy Policy 2008, 36, 4419-4426. [CrossRef]

56. Summerbell, D.L.; Khripko, D.; Barlow, C.; Hesselbach, J. Cost and carbon reductions from industrial demand-side management: Study of potential savings at a cement plant. Appl. Energy 2017, 197, 100-113. [CrossRef]

57. Arun, S.; Selvan, M. Intelligent residential energy management system for dynamic demand response in smart buildings. IEEE Syst. J. 2018, 12, 1329-1340. [CrossRef]

58. Ma, J.; Chen, H.H.; Song, L.; Li, Y. Residential Load Scheduling in Smart Grid: A Cost Efficiency Perspective. IEEE Trans. Smart Grid 2016, 7, 771-784. [CrossRef]

59. Shi, H.; Blaauwbroek, N.; Nguyen, P.H.; Kamphuis, R.I. Energy management in Multi-Commodity Smart Energy Systems with a greedy approach. Appl. Energy 2016, 167, 385-396. [CrossRef]

60. Yaqub, R.; Ahmad, S.; Ahmad, A.; Amin, M. Smart energy-consumption management system considering consumers' spending goals (SEMS-CCSG). Int. Trans. Electr. Energy Syst. 2016, 26, 1570-1584. [CrossRef]

61. Rahi, G.E.; Saad, W.; Glass, A.; Mandayam, N.B.; Poor, H.V. Prospect theory for prosumer-centric energy trading in the smart grid. In Proceedings of the Innovative Smart Grid Technologies Conference (ISGT), USA, 6-9 September 2016; pp. 1-5.

62. Roh, H.T.; Lee, J.W. Residential Demand Response Scheduling with Multiclass Appliances in the Smart Grid. IEEE Trans. Smart Grid 2016, 7, 94-104. [CrossRef]

63. Sumaiti, A.; Saad, A.; Salama, M.A.; Moursi, M.; Mohamed, E. Enabling electricity access in developing countries: A probabilistic weather driven house based approach. Appl. Energy 2017, 191, 531-548. [CrossRef]

64. Guo, Y.; Pan, M.; Fang, Y.; Khargonekar, P. Decentralized Coordination of Energy Utilization for Residential Households in the Smart Grid. IEEE Trans. Smart Grid 2013, 4, 1341-1350. [CrossRef]

65. Mostafa, H.A.; El Shatshat, R.; Salama, M. A Correlated Equilibrium Game-Theoretic Approach for Multiple Participants Electric Distribution Systems Operation. IEEE Trans. Smart Grid 2016, 7, 32-42. [CrossRef]

66. Costanzo, G.T. Demand side optimization in smart and green buildings. In Proceedings of the International Conference: Towards Net Zero Energy Buildings, Copenhagen, Denmark, 30 April 2012.

67. Costanzo, G.; Zhu, G.; Anjos, M.; Savard, G. A System Architecture for Autonomous Demand Side Load Management in Smart Buildings. IEEE Trans. Smart Grid 2012, 3, 2157-2165. [CrossRef]

68. Samadi, P.; Schober, R.; Wong, V. Optimal energy consumption scheduling using mechanism design for the future smart grid. In Proceedings of the IEEE International Conference on Smart Grid Communications (SmartGridComm), Brussels, Belgium, 17-20 October 2011; pp. 369-374, [CrossRef]

69. Andersen, P.; Poulsen, B.; Decker, M.; Traeholt, C.; Ostergaard, J. Evaluation of a Generic Virtual Power Plant framework using service oriented architecture. In Proceedings of the IEEE 2nd International Power and Energy Conference (PECon), Johor Bahru, Malaysia, 1-3 December 2008; pp. 1212-1217. [CrossRef]

70. Lombardi, P.; Powalko, M.; Rudion, K. Optimal operation of a virtual power plant. In Proceedings of the IEEE Power \& Energy Society General Meeting (PES '09), Calgary, AB, Canada, 26-30 July 2009; pp. 1-6.

71. You, S.; Træholt, C.; Poulsen, B. A market-based virtual power plant. In Proceedings of the International Conference on Clean Electrical Power, Capri, Italy, 9-11 June 2009; pp. 460-465.

72. You, S.; Traeholt, C.; Poulsen, B. Generic Virtual Power Plants: Management of distributed energy resources under liberalized electricity market. In Proceedings of the 8th International Conference on Advances in Power System Control, Operation and Management (APSCOM 2009), Hong Kong, China, 8-11 November 2009; pp. 1-6. [CrossRef]

73. Ruiz, N.; Cobelo, I.; Oyarzabal, J. A Direct Load Control Model for Virtual Power Plant Management. IEEE Trans. Power Syst. 2009, 24, 959-966. [CrossRef]

74. Chiu, W.Y.; Sun, H.; Poor, H.V. Energy Imbalance Management Using a Robust Pricing Scheme. IEEE Trans. Smart Grid 2013, 4, 896-904. [CrossRef]

75. Nguyen, H.K.; Song, J.; Han, Z. Demand side management to reduce Peak-to-Average Ratio using game theory in smart grid. In Proceedings of the IEEE Conference on Computer Communications Workshops (INFOCOM WKSHPS), Orlando, FL, USA, 25-30 March 2012; pp. 91-96. [CrossRef] 
76. Muralitharan, K.; Sakthivel, R.; Shi, Y. Multiobjective optimization technique for demand side management with load balancing approach in smart grid. Neurocomputing 2016, 177, 110-119. [CrossRef]

77. Li, D.; Jayaweera, S.; Naseri, A. Auctioning game based Demand Response scheduling in smart grid. In Proceedings of the IEEE Online Conference on Green Communications (GreenCom), New York, NY, USA, 26-29 September 2011; pp. 58-63. [CrossRef]

78. Song, I.K.; Jung, W.W.; Kim, J.Y.; Yun, S.Y.; Choi, J.H.; Ahn, S.J. Operation Schemes of Smart Distribution Networks with Distributed Energy Resources for Loss Reduction and Service Restoration. IEEE Trans. Smart Grid 2013, 4, 367-374. [CrossRef]

79. Liu, Y.; Hassan, N.U.; Huang, S.; Yuen, C. Electricity cost minimization for a residential smart Grid with distributed generation and bidirectional power transactions. In Proceedings of the IEEE PES Innovative Smart Grid Technologies (ISGT), Washington, DC, USA, 24-27 February 2013; pp. 1-6.

80. Xiao, D.; Lu, G.; Liang, R.; Vasilakos, H. False data injection on state estimation in power systems-Attacks, impacts, and defense: A survey. IEEE Trans. Ind. Inform. 2017, 13, 411-423.

81. Jalali, M.M.; Kazemi, A. Demand side management in a smart grid with multiple electricity suppliers. Energy 2015, 81, 766-776. [CrossRef]

82. Mohsenian-Rad, A.H.; Leon-Garcia, A. Optimal Residential Load Control with Price Prediction in Real-Time Electricity Pricing Environments. IEEE Trans. Smart Grid 2010, 1, 120-133. [CrossRef]

83. Mohsenian-Rad, A.H.; Wong, V.W.; Jatskevich, J.; Schober, R. Optimal and autonomous incentive-based energy consumption scheduling algorithm for smart grid. In Proceedings of the Innovative Smart Grid Technologies (ISGT), Gothenburg, Sweden, 19-21 January 2010; pp. 1-6.

84. Hassan, N.U.; Pasha, M.A.; Yuen, C.; Huang, S.; Wang, X. Impact of Scheduling Flexibility on Demand Profile Flatness and User Inconvenience in Residential Smart Grid System. Energies 2013, 6, 6608-6635. [CrossRef]

85. Barbato, A.; Capone, A.; Chen, L.; Martignon, F.; Paris, S. A distributed demand-side management framework for the smart grid. Comput. Commun. 2015, 57, 13-24. [CrossRef]

86. Lujano-Rojas, J.M.; Monteiro, C.; Dufo-López, R.; Bernal-Agustín, J.L. Optimum residential load management strategy for real time pricing (RTP) demand response programs. Energy Policy 2012, 45, 671-679. [CrossRef]

87. Salinas, S.; Li, M.; Li, P.; Fu, Y. Dynamic Energy Management for the Smart Grid with Distributed Energy Resources. IEEE Trans. Smart Grid 2013, 4, 2139-2151. [CrossRef]

88. Wang, Z.; Gu, C.; Li, F.; Bale, P.; Sun, H. Active Demand Response Using Shared Energy Storage for Household Energy Management. IEEE Trans. Smart Grid 2013, 4, 1888-1897. [CrossRef]

89. Babar, M.; Ahamed, T.; Shah, A.; Al-Ammar, E.; Malik, N. Novel algorithm for aggregated demand response strategy for smart distribution network. In Proceedings of the 3rd International Conference on Electric Power and Energy Conversion Systems (EPECS), Istanbul, Turkey, 2-4 October 2013; pp. 1-5. [CrossRef]

90. Kuzlu, M.; Pipattanasomporn, M.; Rahman, S. Hardware Demonstration of a Home Energy Management System for Demand Response Applications. IEEE Trans. Smart Grid 2012, 3, 1704-1711. [CrossRef]

91. Baharlouei, Z.; Hashemi, M. Efficiency-Fairness Trade-off in Privacy-Preserving Autonomous Demand Side Management. IEEE Trans. Smart Grid 2014, 5, 799-808. [CrossRef]

92. Erol-Kantarci, M.; Mouftah, H. Wireless Sensor Networks for Cost-Efficient Residential Energy Management in the Smart Grid. IEEE Trans. Smart Grid 2011, 2, 314-325. [CrossRef]

93. Hubert, T.; Grijalva, S. Modeling for Residential Electricity Optimization in Dynamic Pricing Environments. IEEE Trans. Smart Grid 2012, 3, 2224-2231. [CrossRef]

94. Pipattanasomporn, M.; Kuzlu, M.; Rahman, S. An Algorithm for Intelligent Home Energy Management and Demand Response Analysis. IEEE Trans. Smart Grid 2012, 3, 2166-2173. [CrossRef]

95. Faria, P.; Soares, J.; Vale, Z.; Morais, H.; Sousa, T. Modified Particle Swarm Optimization Applied to Integrated Demand Response and DG Resources Scheduling. IEEE Trans. Smart Grid 2013, 4, 606-616. [CrossRef]

96. Gong, C.; Wang, X.; Xu, W.; Tajer, A. Distributed Real-Time Energy Scheduling in Smart Grid: Stochastic Model and Fast Optimization. IEEE Trans. Smart Grid 2013, 4, 1476-1489. [CrossRef]

97. Atzeni, I.; Ordonez, L.; Scutari, G.; Palomar, D.; Fonollosa, J. Demand-Side Management via Distributed Energy Generation and Storage Optimization. IEEE Trans. Smart Grid 2013, 4, 866-876. [CrossRef]

98. Zhao, Z.; Lee, W.C.; Shin, Y.; Song, K.B. An Optimal Power Scheduling Method for Demand Response in Home Energy Management System. IEEE Trans. Smart Grid 2013, 4, 1391-1400. [CrossRef] 
99. Vivekananthan, C.; Mishra, Y.; Ledwich, G.; Li, F. Demand Response for Residential Appliances via Customer Reward Scheme. IEEE Trans. Smart Grid 2014, 5, 809-820. [CrossRef]

100. Gomez-Herrera, J.A.; Anjos, M.F. Optimal collaborative demand-response planner for smart residential buildings. Energy 2018, 161, 370-380. [CrossRef]

101. Li, P.H.; Pye, S. Assessing the benefits of demand-side flexibility in residential and transport sectors from an integrated energy systems perspective. Appl. Energy 2018, 228, 965-979. [CrossRef]

102. Noor, S.; Yang, W.; Guo, M.; van Dam, K.H.; Wang, X. Energy Demand Side Management within micro-grid networks enhanced by blockchain. Appl. Energy 2018, 228, 1385-1398. [CrossRef]

103. Lu, J.; Sookoor, T.; Srinivasan, V.; Gao, G.; Holben, B.; Stankovic, J.; Field, E.; Whitehouse, K. The smart thermostat: Using occupancy sensors to save energy in homes. In Proceedings of the 8th ACM Conference on Embedded Networked Sensor Systems, Zürich, Switzerland, 3-5 November 2010; ACM: New York, NY, USA, 2010; pp. 211-224.

104. Tsiamitros, D.; Stimoniaris, D.; Poulakis, N.; Zehir, M.; Batman, A.; Bagriyanik, M.; Ozdemir, A.; Dialynas, E. Advanced energy storage and demand-side management in smart grids using buildings energy efficiency technologies. In Proceedings of the IEEE PES Innovative Smart Grid Technologies Conference Europe (ISGT-Europe), Istanbul, Turkey, 12-15 October 2014; pp. 1-6.

105. Pan, J.; Jain, R.; Paul, S. A Survey of Energy Efficiency in Buildings and Microgrids using Networking Technologies. IEEE Commun. Surv. Tutor. 2014, 16, 1709-1731. [CrossRef]

106. Hootman, T. Net Zero Energy Design: A Guide for Commercial Architecture; John Wiley \& Sons: Hoboken, NJ, USA, 2013.

107. Thiel, C.L.; Campion, N.; Landis, A.E.; Jones, A.K.; Schaefer, L.A.; Bilec, M.M. A materials life cycle assessment of a net-zero energy building. Energies 2013, 6, 1125-1141. [CrossRef]

108. Mohsenian-Rad, A.H.; Wong, V.; Jatskevich, J.; Schober, R.; Leon-Garcia, A. Autonomous Demand-Side Management Based on Game-Theoretic Energy Consumption Scheduling for the Future Smart Grid. IEEE Trans. Smart Grid 2010, 1, 320-331. [CrossRef]

109. Ahmad, S.; Naeem, M.; Ahmad, A. Low complexity approach for energy management in residential buildings. Int. Trans. Electr. Energy Syst. 2018, e2680. [CrossRef]

110. Qela, B.; Mouftah, H. Peak Load Curtailment in a Smart Grid Via Fuzzy System Approach. IEEE Trans. Smart Grid 2014, 5, 761-768. [CrossRef]

111. Chai, B.; Chen, J.; Yang, Z.; Zhang, Y. Demand Response Management with Multiple Utility Companies: A Two-Level Game Approach. IEEE Trans. Smart Grid 2014, 5, 722-731. [CrossRef]

112. Pedrasa, M.; Spooner, T.; MacGill, I. Coordinated Scheduling of Residential Distributed Energy Resources to Optimize Smart Home Energy Services. IEEE Trans. Smart Grid 2010, 1, 134-143. [CrossRef]

113. Agnetis, A.; de Pascale, G.; Detti, P.; Vicino, A. Load Scheduling for Household Energy Consumption Optimization. IEEE Trans. Smart Grid 2013, 4, 2364-2373. [CrossRef]

114. Giusti, A.; Salani, M.; Di Caro, G.; Rizzoli, A.; Gambardella, L. Restricted Neighborhood Communication Improves Decentralized Demand-Side Load Management. IEEE Trans. Smart Grid 2014, 5, 92-101. [CrossRef]

115. Soliman, H.; Leon-Garcia, A. Game-Theoretic Demand-Side Management with Storage Devices for the Future Smart Grid. IEEE Trans. Smart Grid 2014, 5, 1475-1485. [CrossRef]

116. Ma, J.; Deng, J.; Song, L.; Han, Z. Incentive Mechanism for Demand Side Management in Smart Grid Using Auction. IEEE Trans. Smart Grid 2014, 5, 1379-1388. [CrossRef]

117. Nguyen, D.T.; Le, L.B. Risk-Constrained Profit Maximization for Microgrid Aggregators with Demand Response. IEEE Trans. Smart Grid 2015, 6, 135-146. [CrossRef]

118. Vidal, A.R.; Jacobs, L.A.; Batista, L.S. An evolutionary approach for the demand side management optimization in smart grid. In Proceedings of the IEEE Symposium on Computational Intelligence Applications in Smart Grid (CIASG), Orlando, FL, USA, 9-12 December 2014; pp. 1-7.

119. Yu, Z.; McLaughlin, L.; Jia, L.; Murphy-Hoye, M.; Pratt, A.; Tong, L. Modeling and stochastic control for Home Energy Management. In Proceedings of the IEEE Power and Energy Society General Meeting, San Diego, CA, USA, 22-26 July 2012; pp. 1-9. [CrossRef]

120. Xu, Y.; Yang, Z.; Gu, W.; Li, M.; Deng, Z. Robust real-time distributed optimal control based energy management in a smart grid. IEEE Trans. Smart Grid 2017, 8, 1568-1579. [CrossRef]

121. Yoon, J.H.; Baldick, R.; Novoselac, A. Dynamic Demand Response Controller Based on Real-Time Retail Price for Residential Buildings. IEEE Trans. Smart Grid 2014, 5, 121-129. [CrossRef] 
122. Chiu, T.C.; Shih, Y.Y.; Pang, A.C.; Pai, C.W. Optimized day-ahead pricing with renewable energy demand-side management for smart grids. IEEE Internet Things J. 2017, 4, 374-383. [CrossRef]

123. Rehman, N.U.; Javaid, N.; Khan, Z.A. An enhanced differential evolution based energy management system for smart grids. In Proceedings of the 2017 31st International Conference on Advanced Information Networking and Applications Workshops (WAINA), Taipei, Taiwan, 27-29 March 2017; pp. 132-137.

124. Son, Y.S.; Pulkkinen, T.; Moon, K.D.; Kim, C. Home energy management system based on power line communication. IEEE Trans. Consum. Electron. 2010, 56, 1380-1386. [CrossRef]

125. Galli, S.; Scaglione, A.; Wang, Z. Power Line Communications and the Smart Grid. In Proceedings of the First IEEE International Conference on Smart Grid Communications (SmartGridComm), Gaithersburg, MD, USA, 4-6 October 2010; pp. 303-308. [CrossRef]

126. Han, D.M.; Lim, J.H. Design and implementation of smart home energy management systems based on zigbee. IEEE Trans. Consum. Electron. 2010, 56, 1417-1425. [CrossRef]

127. Han, J.; Choi, C.S.; Park, W.K.; Lee, I. Green Home Energy Management System through comparison of energy usage between the same kinds of home appliances. In Proceedings of the 15th International Symposium on Consumer Electronics (ISCE), Singapore, 14-17 June 2011; pp. 1-4. [CrossRef]

128. Simshauser, P.; Downer, D. Dynamic Pricing and the Peak Electricity Load Problem. Aust. Econ. Rev. 2012, 45, 305-324. [CrossRef]

129. Conejo, A.; Morales, J.; Baringo, L. Real-Time Demand Response Model. IEEE Trans. Power Syst. 2010, 1, 236-242. [CrossRef]

130. Hartway, R.; Price, S.; Woo, C. Smart meter, customer choice and profitable time-of-use rate option. Energy 1999, 24, 895-903. [CrossRef]

131. Abbasi, B.Z.; Javaid, S.; Bibi, S.; Khan, M.; Malik, M.N.; Butt, A.A.; Javaid, N. Demand Side Management in Smart Grid by Using Flower Pollination Algorithm and Genetic Algorithm. In Proceedings of the International Conference on P2P, Parallel, Grid, Cloud and Internet Computing, Barcelona, Spain, 8-10 November 2017; Springer: Cham, Switzerland, 2017; pp. 424-436.

132. Khan, M.; Khalid, R.; Zaheer, B.; Tariq, M.; Ul Abideen, Z.; Malik, H.; Javaid, N. Residential Demand Side Management in Smart Grid Using Meta-Heuristic Techniques. In Proceedings of the International Conference on P2P, Parallel, Grid, Cloud and Internet Computing, Barcelona, Spain, 8-10 November 2017; Springer: Cham, Switzerland, 2017; pp. 76-88.

133. Yang, P.; Tang, G.; Nehorai, A. Optimal time-of-use electricity pricing using game theory. In Proceedings of the IEEE International Conference on Acoustics, Speech and Signal Processing (ICASSP), Kyoto, Japan, 25-30 March 2012; pp. 3081-3084.

134. Ahmad, J.; Abrar, M. Demand Side Management Based Optimal Energy Management Technique for Smart Grid. Iran. J. Sci. Technol. Trans. Electr. Eng. 2017, 41, 81-91. [CrossRef]

135. Bu, S.; Yu, F.; Cai, Y.; Liu, X. When the Smart Grid Meets Energy-Efficient Communications: Green Wireless Cellular Networks Powered by the Smart Grid. IEEE Trans. Wirel. Commun. 2012, 11, 3014-3024. [CrossRef]

136. Parvania, M.; Fotuhi-Firuzabad, M. Demand Response Scheduling by Stochastic SCUC. IEEE Trans. Smart Grid 2010, 1, 89-98. [CrossRef]

137. Hajj, N.; Awad, M. A Game Theory Approach to DemandSide Management inSmart Grids. In Proceedings of the 7th IEEE International Conference Intelligent Systems IS'2014, Warsaw, Poland, 24-26 September 2014; pp. 807-819.

138. Wolak, F.A. Residential Customer Response to Real-Time Pricing: The Anaheim Critical Peak Pricing Experiment; Center for the Study of Energy Markets: Berkeley, CA, USA, 2007.

139. Tang, Y.; Song, H.; Hu, F.; Zou, Y. Investigation on TOU pricing principles. In Proceedings of the IEEE PES Transmission and Distribution Conference and Exhibition: Asia and Pacific, Dalian, China, 18 August 2005; pp. 1-9. [CrossRef]

140. Mondal, A.; Misra, S.; Obaidat, M.S. Distributed home energy management system with storage in smart grid using game theory. IEEE Syst. J. 2017, 11, 1857-1866. [CrossRef]

141. Chen, J.; Zhu, Q. A Stackelberg Game Approach for Two-Level Distributed Energy Management in Smart Grids. IEEE Trans. Smart Grid 2017. [CrossRef]

142. Mondal, A.; Misra, S.; Patel, L.S.; Pal, S.K.; Obaidat, M.S. DEMANDS: Distributed Energy Management Using Noncooperative Scheduling in Smart Grid. IEEE Syst. J. 2018, 12, 2645-2653. [CrossRef] 
143. Etesami, S.R.; Saad, W.; Mandayam, N.B.; Poor, H.V. Stochastic Games for the Smart Grid Energy Management with Prospect Prosumers. IEEE Trans. Autom. Control 2018, 63, 2327-2342. [CrossRef]

144. Atzeni, I.; Ordonez, L.; Scutari, G.; Palomar, D.; Fonollosa, J. Day-ahead bidding strategies for demand-side expected cost minimization. In Proceedings of the IEEE Third International Conference on Smart Grid Communications (SmartGridComm), Tainan, Taiwan, 5-8 November 2012; pp. 91-96. [CrossRef]

145. Chavali, P.; Yang, P.; Nehorai, A. A Distributed Algorithm of Appliance Scheduling for Home Energy Management System. IEEE Trans. Smart Grid 2014, 5, 282-290. [CrossRef]

146. Cao, Y.; Zhang, G.; Li, D.; Wang, L.; Li, Z. Online Energy Management and Heterogeneous Task Scheduling for Smart Communities with Residential Cogeneration and Renewable Energy. Energies 2018, 11, 2104. [CrossRef]

147. Litos Strategic Communication. The Smart Grid: An Introduction; Technical Report; The U.S. Department of Energy: Washington, DC, USA, 2008.

148. Samuel, O.; Javaid, N.; Ashraf, M.; Ishmanov, F.; Afzal, M.; Khan, Z. Jaya based Optimization Method with High Dispatchable Distributed Generation for Residential Microgrid. Energies 2018, 11, 1513. [CrossRef]

149. Huang, S.; Xiao, J.; Pekny, J.F.; Reklaitis, G.V.; Liu, A.L. Quantifying system-level benefits from distributed solar and energy storage. J. Energy Eng. 2011, 138, 33-42. [CrossRef]

150. Esteban, M.D.; Diez, J.J.; Lopez, J.S.; Negro, V. Why offshore wind energy? Renew. Energy 2011, 36, 444-450. [CrossRef]

151. Li, K.; Bian, H.; Liu, C.; Zhang, D.; Yang, Y. Comparison of geothermal with solar and wind power generation systems. Renew. Sustain. Energy Rev. 2015, 42, 1464-1474. [CrossRef]

152. Patel, M.R. Wind and Solar Power Systems: Design, Analysis, and Operation; CRC Press: Boca Raton, FL, USA, 2005.

153. Kellogg, W.D.; Nehrir, M.H.; Venkataramanan, G.; Gerez, V. Generation unit sizing and cost analysis for stand-alone wind, photovoltaic, and hybrid wind/PV systems. IEEE Trans. Energy Conver. 1998, 13, 70-75. [CrossRef]

154. Khan, J.; Arsalan, M.H. Solar power technologies for sustainable electricity generation-A review. Renew. Sustain. Energy Rev. 2016, 55, 414-425. [CrossRef]

155. Aguiar, J.; Soriano, R.; Gotz, J.; Lemenager, F.; Mosshammer, R.; Gouveia, P. DER and OpenNode: Integration of DG in an open architecture for secondary nodes in the smart grid. In Proceedings of the Integration of Renewables into the Distribution Grid (CIRED Workshop), Lisbon, Portugal, 29-30 May 2012; pp. 1-4.

156. Soriano, R.; Alberto, M.; Collazo, J.; Gonzalez, I.; Kupzog, F.; Moreno, L.; Lugmaier, A.; Lorenzo, J.; Siemens-Austria, A. OpenNode. Open Architecture for Secondary Nodes of the Electricity Smartgrid. In Proceedings of the CIRED 2011 21st International Conference on Electricity Distribution (CD1), Frankfurt, Germany, 6-9 June 2011.

157. Alberto, M.; Soriano, R.; Gotz, J.; Mosshammer, R.; Espejo, N.; Leménager, F.; Bachiller, R. OpenNode: A smart secondary substation node and its integration in a distribution grid of the future. In Proceedings of the Federated Conference on Computer Science and Information Systems (FedCSIS), Wroclaw, Poland, 9-12 September 2012; pp. 1277-1284.

158. Su, S.Y.; Lu, C.N.; Chang, R.F.; Gutierrez-Alcaraz, G. Distributed Generation Interconnection Planning: A Wind Power Case Study. IEEE Trans. Smart Grid 2011, 2, 181-189. [CrossRef]

159. Liang, J.; Venayagamoorthy, G.; Harley, R. Wide-Area Measurement Based Dynamic Stochastic Optimal Power Flow Control for Smart Grids with High Variability and Uncertainty. IEEE Trans. Smart Grid 2012, 3, 59-69. [CrossRef]

160. Papavasiliou, A.; Oren, S. Supplying renewable energy to deferrable loads: Algorithms and economic analysis. In Proceedings of the IEEE Power and Energy Society General Meeting, Providence, RI, USA, 25-29 July 2010; pp. 1-8. [CrossRef]

161. Neely, M.J.; Tehrani, A.S.; Dimakis, A.G. Efficient algorithms for renewable energy allocation to delay tolerant consumers. In Proceedings of the First IEEE International Conference on Smart Grid Communications (SmartGridComm), Gaithersburg, MD, USA, 4-6 October 2010; pp. 549-554.

162. Wolfs, P.; Gunathilake, C.; Martino, P.; Khanna, I. Distributed renewables and battery storage for the support of the edge of the rural grid. In Proceedings of the 21st Australasian Universities Power Engineering Conference (AUPEC), Brisbane, Queensland, Australia, 25-28 September 2011; pp. 1-6. 
163. Kok, K.; Karnouskos, S.; Nestle, D.; Dimeas, A.; Weidlich, A.; Warmer, C.; Strauss, P.; Buchholz, B.; Drenkard, S.; Hatziargyriou, N.; et al. Smart houses for a smart grid. In Proceedings of the 20th International Conference and Exhibition on Electricity Distribution-Part 1 (CIRED), Prague, Czech Republic, 8-11 June 2009; pp. 1-4.

164. Lightner, E.; Widergren, S. An Orderly Transition to a Transformed Electricity System. IEEE Trans. Smart Grid 2010, 1, 3-10. [CrossRef]

165. Avritzer, A.; Suresh, S.; Menasché, D.S.; Leão, R.M.M.; de Souza e Silva, E.; Diniz, M.C.; Trivedi, K.; Happe, L.; Koziolek, A. Survivability models for the assessment of smart grid distribution automation network designs. In Proceedings of the 4th ACM/SPEC International Conference on Performance Engineering, Prague, Czech Republic, 21-24 April 2013; ACM: New York, NY, USA, 2013; pp. 241-252.

166. Peik-herfeh, M.; Seifi, H.; Sheikh-El-Eslami, M.K. Two-stage approach for optimal dispatch of distributed energy resources in distribution networks considering virtual power plant concept. Int. Trans. Electr. Energy Syst. 2014, 24, 43-63. [CrossRef]

167. Caldon, R.; Patria, A.R.; Turri, R. Optimal control of a distribution system with a virtual power plant. In Proceedings of the Bulk Power System Dynamics and Control-VI, Cortina d'Ampezzo, Italy, 22-27 August 2004; pp. 278-284.

168. Hatami, A.; Seifi, H.; Sheikh-el Eslami, M. A Stochastic-Based Decision-Making Framework for an Electricity Retailer: Time-of-Use Pricing and Electricity Portfolio Optimization. IEEE Trans. Power Syst. 2011, 26, 1808-1816. [CrossRef]

(C) 2018 by the authors. Licensee MDPI, Basel, Switzerland. This article is an open access article distributed under the terms and conditions of the Creative Commons Attribution (CC BY) license (http://creativecommons.org/licenses/by/4.0/). 